\title{
新型二维材料光催化与电催化研究进展
}

\author{
李 能, 孔周舟, 陈星竹, 杨雨菲 \\ (武汉理工大学 硅酸盐建筑材料国家重点实验室, 武汉 430070)
}

\begin{abstract}
摘 要: 二维材料以其丰富多样的性能受到广泛关注。该类材料具有极高的比表面积, 可以作为光催化剂和电催化 剂, 在环境领域和可再生能源领域具有较大的开发和应用前景。本文综述了三种新型二维材料的结构性能, 即二维 过渡金属碳/氮化物(MXenes)、类石墨相氮化碳 $\left(\mathrm{g}_{-} \mathrm{C}_{3} \mathrm{~N}_{4}\right)$ 以及黑磷 $(\mathrm{BP})$ 在光催化或电催化领域的研究进展及改性方式; 对二维材料催化性能的改性进行了总结, 并展望了今后的研究方向。
\end{abstract}

关 键 词: 新型二维材料; 光催化; 电催化; 过渡金属碳/氮化物; 类石墨相氮化碳; 黑磷; 综述 中图分类号: TQ174 文献标识码: A

\section{Research Progress of Novel Two-dimensional Materials in Photocatalysis and Electrocatalysis}

\author{
LI Neng, KONG Zhouzhou, CHEN Xingzhu, YANG Yufei
}

(State Key Laboratory of Silicate Materials for Architectures, Wuhan University of Technology, Wuhan 430070, China)

\begin{abstract}
Two-dimensional materials have attracted broad interest because of their wide variety of properties. They can be used as photocatalysts and electrocatalysts due to their extremely high specific surface area, and have great potential application in the field of environment and renewable energy. This review focuses on the structure and properties of common two-dimensional materials such as 2D carbides and nitrides (MXenes), g- $\mathrm{C}_{3} \mathrm{~N}_{4}$ and black phosphorus (BP). Furthermore, the latest research on the modification of two-dimensional materials in the area of photocatalysis and electrocatalysis are discussed and commented. Finally, research prospects for two-dimensional materials in the future are predicted.
\end{abstract}

Key words: novel two-dimensional materials; photocatalysis; electrocatalysis; MXenes; g- $\mathrm{C}_{3} \mathrm{~N}_{4}$; black phosphorous; review

二维材料也被称为“单层材料”, 是一类具有超 过 100 纳米或者几微米甚至更大尺寸, 但是厚度只 有一个或几个原子厚的层状结晶材料。其中, 最早 受到关注的二维材料石墨烯, 是一种平面单层紧密 打包成的二维蜂窝晶格结构, 具有极高的室温载流 子迁移率、量子霍尔效应、极高的比表面积、较高 的杨氏模量、良好的光学透过性以及良好的导电导 热性能等 ${ }^{[1-2]}$ 。自 2004 年单层石墨烯被成功分离以来, 其他类石墨烯二维材料的研究也获得了较大的进展,
出现了如类石墨相氮化碳 $\left(\mathrm{g}-\mathrm{C}_{3} \mathrm{~N}_{4}\right)^{[3-5]}$ 、二维过渡金 属碳/氮化物 (MXenes) ${ }^{[6-8]}$ 、二维过渡金属硫化物 $(\mathrm{TMDs})^{[9-11]}$ 、黑磷(BP) ${ }^{[12-13]}$ 、六方氮化硼 $(\mathrm{h}-\mathrm{BN})^{[14-15]}$ 、 层状双氢氧化物 $(\mathrm{LDHs})^{[16-17]}$ 、层状金属氧化物 ${ }^{[18]}$ 、 金属有机框架化合物(MOFs) ${ }^{[19-20]}$ 、共价有机框架化合 物 $(\mathrm{COFs})^{[21]}$ 、二维聚合物 ${ }^{[22]} 、$ 硅烯 ${ }^{[23]} 、$ 锑烯 ${ }^{[24]}$ 、无 机钙铁矿 ${ }^{[25]}$ 以及有机无机杂化钙钛矿 ${ }^{[26]}$ 等二维功 能材料(如图 1 所示)。这些材料与石墨烯具有相似 的结构特点，但在元素组成上不尽相同，因此也具

收稿日期: 2019-07-25; 收到修改稿日期：2019-11-06

基金项目: 国家自然科学基金(11604249); 教育部霍英东青年教师基金(161008) National Natural Science Foundation of China (11604249); Young Teacher Award by Fok Ying Tong Education Foundation (161008)

作者简介: 李 能(1981-), 男, 博士，研究员. E-mail: lineng@whut.edu.cn LI Neng(1981-), male, PhD, professor. E-mail: lineng@whut.edu.cn 


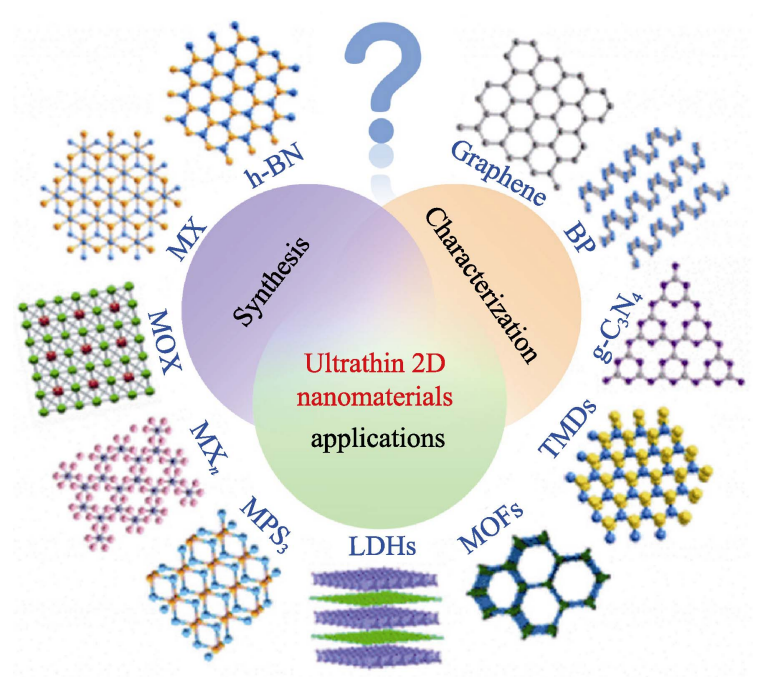

图 1 不同种类的二维材料示意图 ${ }^{[27]}$

Fig. 1 Different types of two-dimensional materials ${ }^{[27]}$

有各自的独特性能, 从而在电子器件、光电器件、 催化和能源等领域表现出广阔的应用前景。据文献 报道，目前超过 700 种二维材料被证明可以稳定存 在, 不过还有许多结构没有合成出来 ${ }^{[28]}$ 。因此为了 有效篮选这些结构, 研究者们对二维材料进行了大 量理论研究。

二维材料以其优异的比表面积与可调的工程结 构, 自诞生以来就被广泛应用于催化领域, 例如析 氢反应 $(H E R) 、$ 析氧反应 $(O E R) 、$ 氧还原反应 $(O R R)$ 二氧化碳还原反应 $\left(\mathrm{CO}_{2} \mathrm{RR}\right)$ 、氮气还原反应 $\left(\mathrm{N}_{2} \mathrm{RR}\right)$ 以及污染物的降解等。如何在保证材料稳定性的同 时改善其催化性能是当前二维材料光电催化的主要 研究方向。本文将总结常见二维材料的光催化和电 催化性能及其改性, 并对其未来的发展进行展望。

\section{1 常见的二维材料}

\section{1 二维过渡金属碳/氮化物(MXenes)}

MXenes 材料是一种二维层状结构的过渡金属 碳/氮化物, 这是一类新型的二维功能材料。2011 年 由美国德雷塞尔大学的 Michel Barsoum 和 Yury Gogotsi 教授团队 ${ }^{[29]}$ 首次发现并报道, 并引起了学 术界的广泛关注。MAX 相陶瓷是一类三元层状结 构化合物，其结构通式为 $\mathrm{M}_{n+1} \mathrm{AX}_{n}(n=1,2,3)$ ，其中 $\mathrm{M}$ 代表过渡金属元素(如 $\mathrm{Ti} 、 \mathrm{~V} 、 \mathrm{Cr} 、 \mathrm{Nb}$ 等元素), $\mathrm{A}$ 是III和IV 主族元素(如 $\mathrm{Al} 、 \mathrm{Si} 、 \mathrm{Sn}$ 、In 等元素), $\mathrm{X}$ 代 表 C、 $\mathrm{N}$ 元素或者两者皆有 ${ }^{[30-31]}$ 。MAX 相的空间点 群为 $\mathrm{P}_{3} / \mathrm{mmc}$, 其中 $\mathrm{M}$ 层原子六方紧密堆积, $\mathrm{X}$ 原子 填充八面体间隙, 而 $\mathrm{A}$ 元素以金属键与 $\mathrm{M}$ 元素连接, 并在 $\mathrm{M}_{n+1} \mathrm{X}_{n}$ 层之间交错排布。 $\mathrm{M}-\mathrm{A}$ 键的活性比
$\mathrm{M}-\mathrm{X}$ 键高 ${ }^{[32-33]}$, 因此使用强刻蚀性的氢氟酸 HF 可以 选择性地将其中的 $\mathrm{A}$ 层原子刻蚀掉，从而获得 $\mathrm{M}_{n+1} \mathrm{X}_{n}$ 结构 ${ }^{[34]}$ 。由于经湿法 HF 刻蚀制备之后, M-A 键将会由 相对较弱的表面作用取代，包括-F、-O、-OH 三种 ${ }^{[35]}$ 。 因此实际合成的 MXenes 结构分子式为 $\mathrm{M}_{n+1} \mathrm{X}_{n} \mathrm{~T}_{x}$, 其中 $\mathrm{T}$ 代表表面的官能团, $x$ 则为表面官能团的数 量。如图 2 所示, 当 $n=1$ 时, MXenes 结构式为 $\mathrm{M}_{2} \mathrm{X}$, 为 “ 21 ”型 MXene; 当 $n=2$ 时, MXenes 结构式为 $\mathrm{M}_{3} \mathrm{X}_{2}$, 为“32”型 MXene; 当 $n=3$ 时, MXenes 结构式为 $\mathrm{M}_{4} \mathrm{X}_{3}$, 为“43”型 MXene。

MXenes 是一种能带结构易于调节的二维材料, 具有优异的性能。作为一种良好的导体, MXene 材 料可以作为一种光催化剂和电催化剂, 在环境领 域和可再生能源领域具有较大的开发和应用前景。 MXene 材料作为催化剂可以用于催化水分解的析 氢反应 $(H E R)$ 和析氧反应 $(O E R) 、 二$ 二氧化碳的还原 反应 $\left(\mathrm{CO}_{2} \mathrm{RR}\right)$ 、氮气的还原反应 $\left(\mathrm{N}_{2} \mathrm{RR}\right)$ 以及污染物 的降解 ${ }^{[8]}$ 。

$\mathrm{Ma}$ 等 ${ }^{[36]}$ 将 MXene 材料 $\mathrm{Ti}_{3} \mathrm{C}_{2}$ 与 $\mathrm{g}-\mathrm{C}_{3} \mathrm{~N}_{4}$ 纳米片 复合在碱性环境中催化 OER 反应，可以实现较高的 反应活性和反应循环次数。也有报道将 MXene 材料 $\mathrm{Ti}_{3} \mathrm{C}_{2} \mathrm{~T}_{x}$ 与二维 MOFs 材料 CoBDC 复合, 与单独的 两种材料相比实现了较高的 OER 催化活性 ${ }^{[37]}$ 。除 此之外, $\mathrm{Yu}$ 等 ${ }^{[38]}$ 还将 MXenes 材料 $\mathrm{Ti}_{3} \mathrm{C}_{2}$ 与 $\mathrm{LDHs}$ 材料 FeNi-LDH 复合对 OER 进行催化, 也表现出良 好的催化活性。Zhou 等 ${ }^{[39]}$ 使用多种单层 MXenes 材 料与 $\mathrm{N}$ 掺杂的石墨烯复合构建异质结构, 并研究了 其催化氧还原反应(ORR)的催化性能。如图 3 (a)所
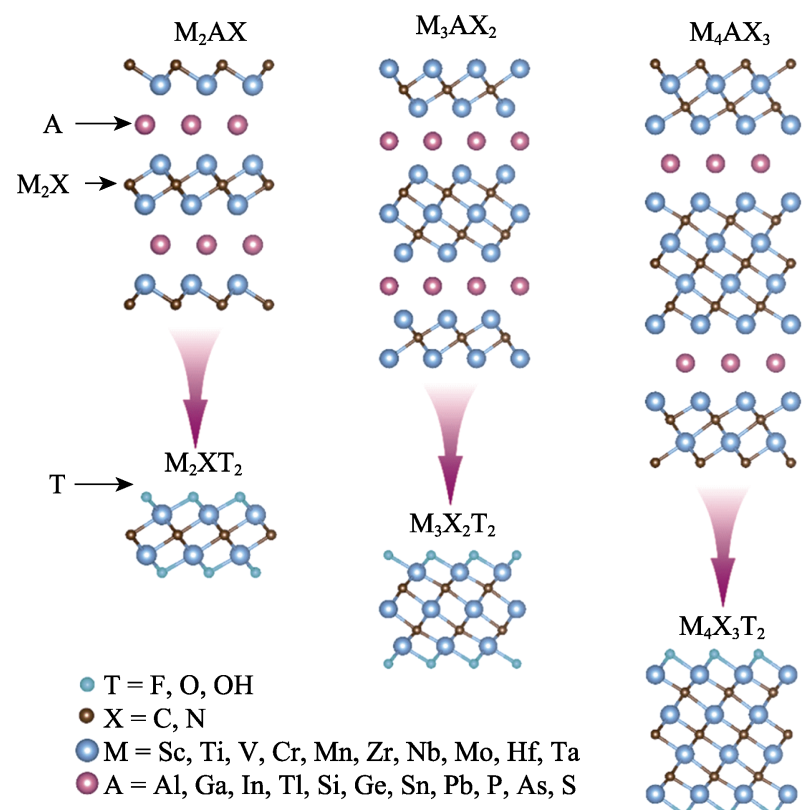

图 2 MAX 及对应 MXene 的结构示意图 ${ }^{[8]}$

Fig. 2 Structures of MAX and corresponding MXene ${ }^{[8]}$ 
(a)

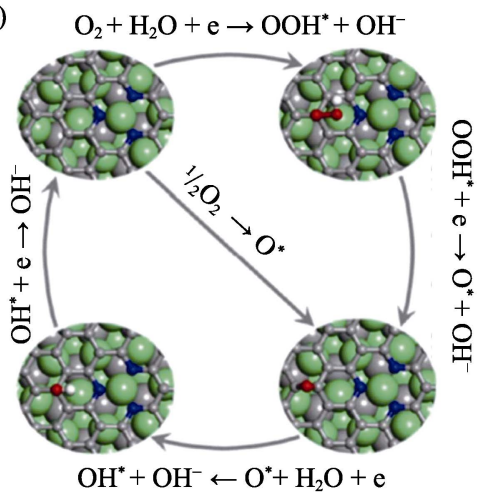

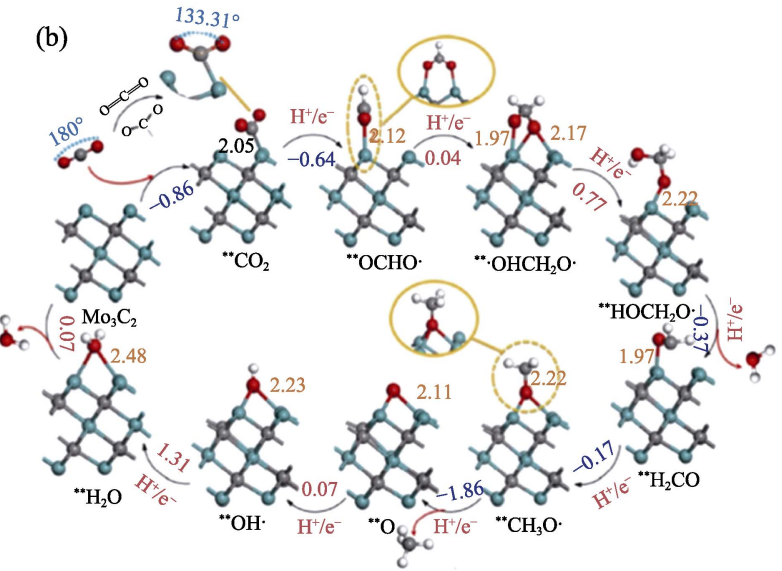

(c)
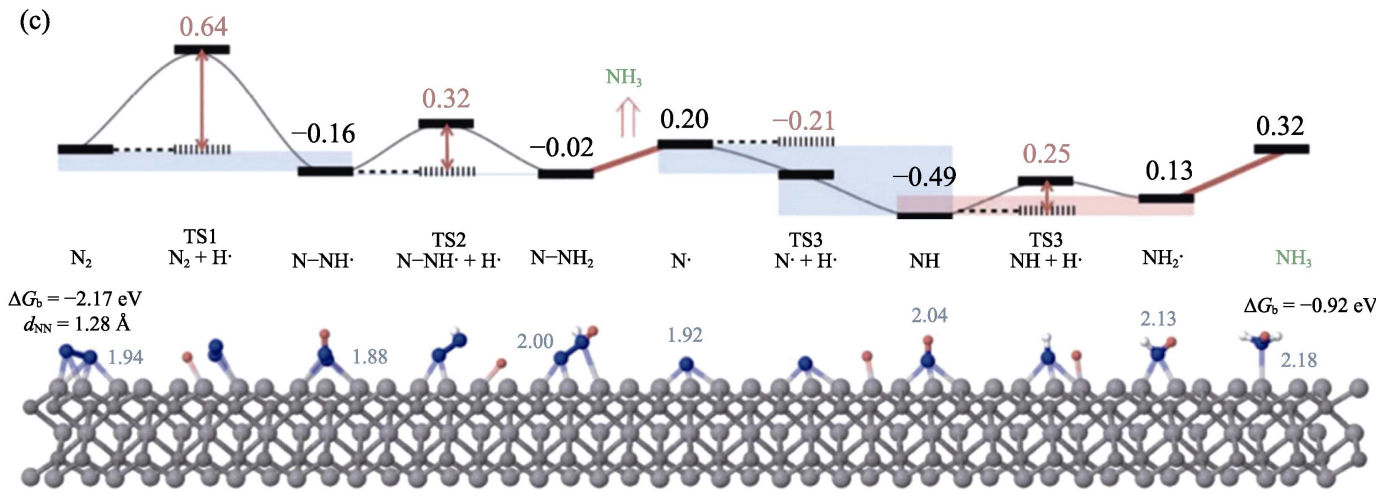

图 3 (a) $\mathrm{N}$ 掺杂石墨烯 $/ \mathrm{V}_{2} \mathrm{C}$ MXene 复合结构表面的 $\mathrm{ORR}$ 示意图 ${ }^{[39]}$, (b) $\mathrm{Mo}_{3} \mathrm{C}_{2} \mathrm{MXene}$ 表面的 $\mathrm{CO}_{2} \mathrm{RR}$ 示意图 ${ }^{[41]}$,

(c) $\mathrm{V}_{3} \mathrm{C}_{2}$ MXene 表面的 $\mathrm{N}_{2} \mathrm{RR}$ 示意图 ${ }^{[42]}(1 \AA=0.1 \mathrm{~nm})$

Fig. 3 (a) ORR schematic diagram of the surface of $\mathrm{N}$-doped graphene/ $\mathrm{V}_{2} \mathrm{C}$ MXene composite structure ${ }^{[39]}$, (b) schematic diagram of $\mathrm{CO}_{2} \mathrm{RR}$ of $\mathrm{Mo}_{3} \mathrm{C}_{2}$ MXene surface ${ }^{[41]}$, (c) schematic diagram of $\mathrm{N}_{2} \mathrm{RR}$ of $\mathrm{V}_{3} \mathrm{C}_{2}$ MXene surface ${ }^{[42]}(1 \AA=0.1 \mathrm{~nm})$

示，他们构建了不同的过渡金属碳化物 MXenes 与 $\mathrm{N}$ 掺杂石墨烯的二维/二维复合结构模型，并采用第一 性原理进行优化处理和模拟计算，表明此类异质结 构具有比较稳定的结构和理想的 ORR 催化活性。

Zhang 等 ${ }^{[40]}$ 同样使用第一性原理模拟计算的方 法，在“2 1 ”型二维 MXene 材料 $\mathrm{Ti}_{2} \mathrm{CO}_{2}$ 表面固定了一 个 $\mathrm{Ti}$ 原子, 通过这个 $\mathrm{Ti}$ 原子实现单原子催化氧化一 氧化碳分子, 他们还讨论了 $\mathrm{CO}$ 氧化的两种机理, 并计算了 $\mathrm{CO} \rightarrow \mathrm{CO}_{2}$ 中间过渡态的能量, 最终计算 结果表明在 MXene 表面负载单原子进行催化氧化 $\mathrm{CO}$ 是完全可行的。

本课题组 ${ }^{[41]}$ 也曾使用第一性原理计算的方法 研究了“32”型 MXenes 材料还原二氧化碳的催化反 应过程。MXenes 材料具有比较大的比表面积, 且材 料表面对 $\mathrm{CO}_{2}$ 分子具有良好的吸附活性, 因而可以 使用 MXenes 材料捕获并吸附空气中的 $\mathrm{CO}_{2}$ 小分 子。如图 3 (b)所示, 我们还对 $\mathrm{CO}_{2}$ 在 MXene 表面 的转化过程进行了系统的模拟, 发现 MXene 材料可 以将 $\mathrm{CO}_{2}$ 分子转化为碳氢化合物等清洁能源。进一 步讨论了不同的官能团表面对 MXenes 材料的催化
转化 $\mathrm{CO}_{2}$ 性能的影响, 表面清洁无官能团吸附的 MXenes 和表面吸附有官能团的 MXenes 均具有一 定程度的催化活性。

本课题组 ${ }^{[42]}$ 还报道了 MXene 材料用于催化固 氮合成氨反应的前景, 研究使用第一性原理的方法 比较了 $\mathrm{d} 2-\mathrm{d} 4$ 的 8 种“32”型 MXene 材料对于氮气的 捕获和吸附情况，结果表明氮气在 MXene 材料表面 可以实现良好的化学吸附。研究模拟了 $\mathrm{N}_{2}$ 在 MXene 表面逐步加氢还原的过程, 并充分考虑了氮气加氢还 原过程中的各种路径和中间过渡态的能量。如图 3(c) 所示, 计算结果表明 $\mathrm{N}_{2}$ 在 MXene 表面上可以实现 $\mathrm{N}_{2} \rightarrow \mathrm{NH}_{3}$ 的转化, 这说明 MXenes 材料在固氮合成 氨领域也具有光明的前景, 这项工作对 MXene 催化 固氮合成氨提供了重要的理论指导。

Zhao 等 ${ }^{[43]}$ 制备了具有丰富的钛缺位缺陷和高 还原能力的 $\mathrm{Ti}_{3-x} \mathrm{C}_{2} \mathrm{~T}_{y}$, 并使用铂基单原子 MXenes 催化剂 $\mathrm{Pt}_{1} / \mathrm{Ti}_{3-x} \mathrm{C}_{2} \mathrm{~T}_{y}$ 对 $\mathrm{CO}_{2}$ 气体吸附和有机合成进 行了催化研究, 发现该材料可以通过活化 $\mathrm{CO}_{2}$ 使胺 和硅烷反应生成甲酰胺。深入研究发现 $\mathrm{Ti}$ 空位仅对 单原子起到稳定作用, 对催化活性的影响不显著。与 
该催化体系中的其他催化剂相比, 铂负载的 $\mathrm{Ti}_{3-x} \mathrm{C}_{2} \mathrm{~T}_{y}$ 材料在相对温和的反应条件下具有 $\mathrm{CO}_{2}$ 压 力小、贵金属含量极低的优点, 并且产率和选择性 优异。

MXenes 材料在 HER 反应中也表现出相当优异 的催化性能。有学者通过第一性原理计算评估了 17 种“21”型 MXene 材料的 HER 催化活性 ${ }^{[44]}$, 其中 $\mathrm{Ti}_{2} \mathrm{CO}_{2}$ 和 $\mathrm{W}_{2} \mathrm{CO}_{2}$ 具有较低的氢吸附自由能 $\Delta G_{\mathrm{H}}$, 其 绝对值约为 $0.12 \mathrm{eV}$, 与 $\mathrm{Pt}(111)$ 面的 $\Delta G_{\mathrm{H}}$ 值 $(-0.09 \mathrm{eV})$ 相近, 表明它们具有良好的催化 HER 性能。双金属 MXene 由于存在两种过渡金属, 其表面用于吸附质 子的 $\mathrm{O}$ 原子也处于不同的环境中, 其中 $\mathrm{OTi}_{2} \mathrm{~V}_{1}$ 位点 的 $\Delta G_{\mathrm{H}}$ 甚至达到 $0.01 \mathrm{eV}$, 低于 $\operatorname{Pt}(111)$ 面的值, 且接 近于零。Guo 等 ${ }^{[55]}$ 也计算了 “ 21 ”型 MXene 材料的价 带底(VBM)和导带顶(CBM)的位置, 计算结果表明 $\mathrm{Zr}_{2} \mathrm{CO}_{2}$ 和 $\mathrm{Hf}_{2} \mathrm{CO}_{2}$ 材料的 $\mathrm{VBM}$ 和 $\mathrm{CBM}$ 的位置与氢 气还原电势 $\mathrm{H}^{+} / \mathrm{H}_{2}$ 和水氧化电势 $\mathrm{H}_{2} \mathrm{O} / \mathrm{O}_{2}$ 的位置相匹 配，表明这两类 MXenes 同时具有 HER 和 OER 的 催化活性。Ling 等 ${ }^{[46]}$ 还在 $\mathrm{V}_{2} \mathrm{CO}_{2}$ 的表面负载过渡金 属原子 $(\mathrm{Fe} 、 \mathrm{Co} 、 \mathrm{Ni})$, 并在负载原子上进行催化 HER 反应的模拟。如图 4(a)所示, 过渡金属在 $\mathrm{V}_{2} \mathrm{CO}_{2}$ 表
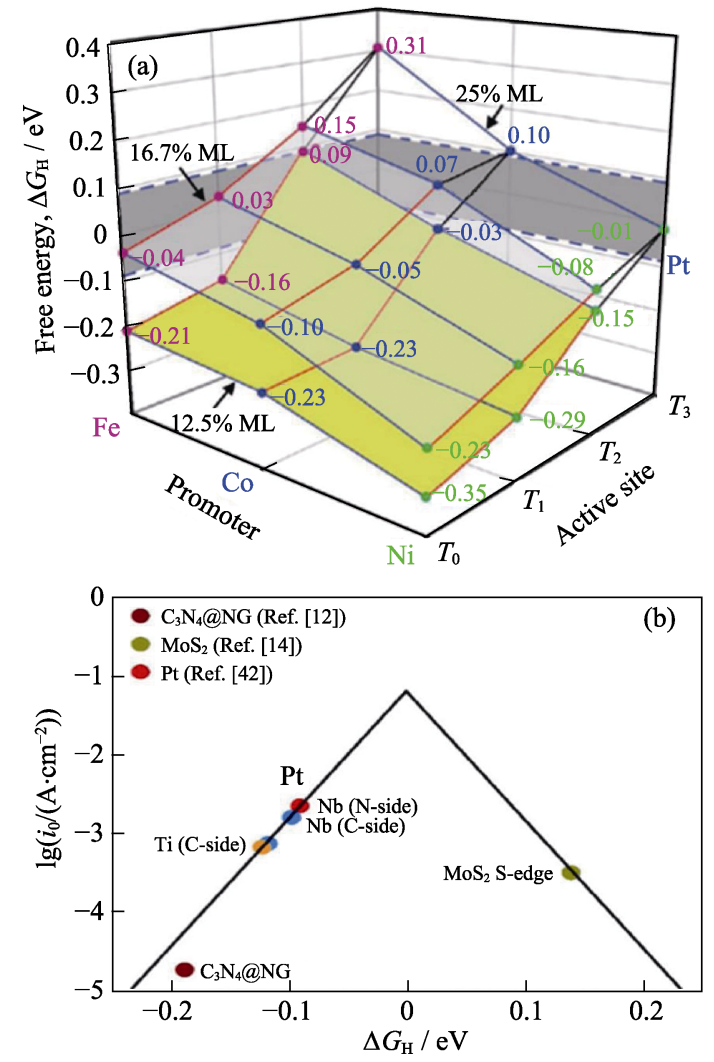

图 4 (a)过渡金属原子负载的 $\mathrm{V}_{2} \mathrm{CO}_{2} \mathrm{MXene}$ 表面的氢原子吸 附自由能 ${ }^{[46]}$ 和(b) $\mathrm{M}_{3} \mathrm{CNO}_{2}$ 型 MXene 的 HER 活性火山图 ${ }^{[35]}$

Fig. 4 (a) Hydrogen adsorption free energy of $\mathrm{V}_{2} \mathrm{CO}_{2}$ MXene surface supported by transition metal atom ${ }^{[46]}$ and (b) HER active volcano map of $\mathrm{M}_{3} \mathrm{CNO}_{2}$ type MXene ${ }^{[35]}$
面的吸附可以极大改进 $\mathrm{V}_{2} \mathrm{CO}_{2}$ 的 HER 催化活性, 通 过调节过渡金属原子在表面吸附的浓度，也可以对 其催化活性进行有效调控 ${ }^{[47]}$ 。 $\mathrm{Li}$ 等 ${ }^{[48]}$ 也进行了大通 量的计算，通过过渡金属在 MXene 表面的修饰对 MXene 材料的催化性能进行了改进。

Wang 等 ${ }^{[49]}$ 则将 MXene 材料 $\mathrm{Ti}_{3} \mathrm{C}_{2} \mathrm{~T}_{x}$ 与 $\mathrm{TiO}_{2}$ 复 合, 实现了光催化 HER 反应, 相比于只使用 $\mathrm{TiO}_{2}$ 进行光催化 HER 反应, 复合体系的产氢速率得到明 显提高。Ran 等 ${ }^{[50]}$ 则将 MXene 材料与金属硫化物进 行组合, 也实现了高效的光催化析氢, DFT 计算结 果表明 MXene 材料具有优异的 HER 催化活性。不 同学者分别将“21”型和“32”型 MXenes 材料与 $\mathrm{g}-\mathrm{C}_{3} \mathrm{~N}_{4}$ 复合, 进行光催化析氢反应, 都取得了较好 的效果 ${ }^{[51-52]}$ 。

作为一种优良的导体, MXene 材料在电催化 HER 领域也取得了很大的进步 ${ }^{[52-55]}$ 。Pandey 等 ${ }^{[53]}$ 采 用模拟计算方法对含有不同过渡金属的“ 21 ”型、“32” 型和“43”型的 MXene 建立了电催化 HER 性能数据库, 同时还比较了 MXene 表面的几种官能团的影响, 研 究发现 MXene 材料表面含有-O 官能团时表现出最 优秀的催化性能。Seh 研究团队 ${ }^{[54]}$ 从理论和实验的角 度分别论证了“21”型 MXenes 材料在电催化 HER 反 应的催化性能, 通过比较大量不同金属元素组成的 MXenes 的 $\Delta G_{\mathrm{H}}$, 发现 $\mathrm{Mo}_{2} \mathrm{CT}_{x}$ 是最良好的催化剂。 $\mathrm{Li}$ 等 ${ }^{[55]}$ 也采用第一性原理计算的方法, 研究了两种 非金属元素的“32”型 MXene 材料 $\mathrm{M}_{3} \mathrm{CNT}_{x}$ 作为电催 化剂在 HER 反应中的催化性能和机理, 同时也讨论 了单金属原子修饰的 $\mathrm{M}_{3} \mathrm{CNT}_{x}$ 电催化 HER 性能。如 图 4 (b) 所示, $\mathrm{N}$-side 的 $\mathrm{Nb}_{3} \mathrm{CNO}_{2}$ 的位置与 $\mathrm{Pt}$ 的位置 相接近, 表明它可以产生更高的交换电流, 促进析氢 反应过程中氢吸附脱附的发生, 同时通过比较表面 含有不同浓度的氢覆盖率的 $\Delta G_{\mathrm{H}}$ 也可以发现在某些 特定的氢覆盖率下, MXene 表面具有极高的 HER 电 催化活性, 这也为调控 MXene 表面氢浓度实现高效 HER 催化提供了重要的理论依据。

\section{2 类石墨相氮化碳 $\left(\mathrm{g}-\mathrm{C}_{3} \mathrm{~N}_{4}\right)$}

与二维功能材料的研究和应用历史不同, 氮化 碳 $\left(\mathrm{C}_{3} \mathrm{~N}_{4}\right)$ 聚合物材料的文献报道甚至可以追溯到 19 世纪。1 834 年, Berzelius 成功合成了氮化碳化合物, 并由 Liebig 对其进行了命名 ${ }^{[3]}$ 。1996 年, Teter 等 ${ }^{[56]}$ 采用第一性原理方法对氮化碳化合物的结构进行了 精确测算, 提出了氮化碳的五种不同的晶体结构: $\alpha-\mathrm{C}_{3} \mathrm{~N}_{4}$ 相、 $\beta-\mathrm{C}_{3} \mathrm{~N}_{4}$ 相、立方 $\mathrm{C}_{3} \mathrm{~N}_{4}$ 相、准立方 $\mathrm{C}_{3} \mathrm{~N}_{4}$ 相和类石墨 $\mathrm{C}_{3} \mathrm{~N}_{4}$ 相。类石墨 $\mathrm{C}_{3} \mathrm{~N}_{4}$ 即 $\mathrm{g}-\mathrm{C}_{3} \mathrm{~N}_{4}$ 的结构 是最稳定的, 具有类似于石墨的层状结构, 其中 $\mathrm{C}$ 原子与 $\mathrm{N}$ 原子之间以 $\mathrm{sp}^{2}$ 杂化形成高度离域的 $\pi$ 共 
轭体系。 $\mathrm{g}-\mathrm{C}_{3} \mathrm{~N}_{4}$ 存在两种基本的结构组成单元: 三 嗪环 $\left(\mathrm{C}_{3} \mathrm{~N}_{3}\right)$ 和 3-s-三嗪环/庚嗪环 $\left(\mathrm{C}_{6} \mathrm{~N}_{7}\right)$ 。三嗪环基 $g-C_{3} N_{4}$ 和庚嗪环基 $g-\mathrm{C}_{3} \mathrm{~N}_{4}$ 是 $\mathrm{g}-\mathrm{C}_{3} \mathrm{~N}_{4}$ 的两种同素异 形体。Kroke 等 ${ }^{[57]}$ 使用 DFT 计算的方法分别计算了 两种结构的能量, 结果表明庚嗪环基 $\mathrm{g}-\mathrm{C}_{3} \mathrm{~N}_{4}$ 的能量 相对较低, 是 $\mathrm{C}_{3} \mathrm{~N}_{4}$ 在热力学上最稳定的一个相。在 后文所提及的 $\mathrm{g}-\mathrm{C}_{3} \mathrm{~N}_{4}$ 中, 如果没有特殊说明, 都是 指庚嗪环基 $\mathrm{g}-\mathrm{C}_{3} \mathrm{~N}_{4}$ 。

研究表明, $\mathrm{g}-\mathrm{C}_{3} \mathrm{~N}_{4}$ 无毒且对环境无污染, 属于 环境友好型材料, 并且具有以下性质：(1) $g-\mathrm{C}_{3} \mathrm{~N}_{4}$ 的 禁带宽度为 $2.7 \sim 2.8 \mathrm{eV}$, 可以吸收太阳光谱中 450 $460 \mathrm{~nm}$ 的可见光部分; (2) $\mathrm{g}-\mathrm{C}_{3} \mathrm{~N}_{4}$ 的导带 $(-1.2 \mathrm{~V}$ ( vs. $\mathrm{NHE})$ ) 和价带 $(+1.5 \mathrm{~V}$ (vs. NHE) ) 跨过了水的氧化还 原窗口; (3) $g-\mathrm{C}_{3} \mathrm{~N}_{4}$ 具有极高的化学稳定性和较高的 热稳定性; (4) $\mathrm{g}-\mathrm{C}_{3} \mathrm{~N}_{4}$ 作为一种聚合物材料, 可以在 分子水平通过表面工程对其表面性质进行有效调控,

(a)

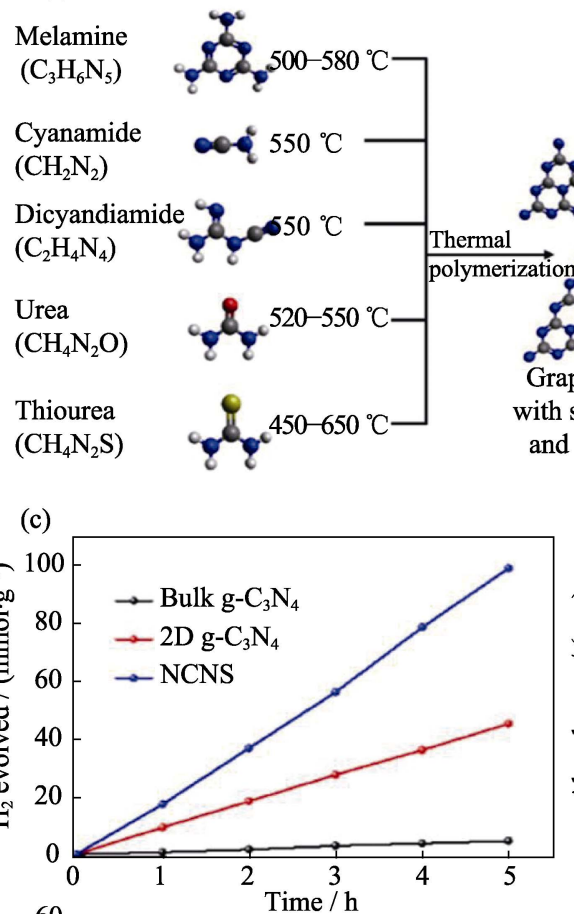

并且成本低廉，易于制备。

上述特性使 $\mathrm{g}-\mathrm{C}_{3} \mathrm{~N}_{4}$ 成为一种具有极具竞争力 的半导体光催化剂。2009 年, Wang 等 ${ }^{[58]}$ 发现 $\mathrm{g}-\mathrm{C}_{3} \mathrm{~N}_{4}$ 可用于可见光下催化 HER 反应, 便引起了学术界对 应用 $\mathrm{g}-\mathrm{C}_{3} \mathrm{~N}_{4}$ 作为光催化剂的研究热潮。目前 $\mathrm{g}-\mathrm{C}_{3} \mathrm{~N}_{4}$ 被广泛应用在光催化水分解、光催化降解有机染料 和光催化有机合成等领域 ${ }^{[59]}$ 。

在 $\mathrm{g}-\mathrm{C}_{3} \mathrm{~N}_{4}$ 的实际应用中, 研究人员发现 $\mathrm{g}-\mathrm{C}_{3} \mathrm{~N}_{4}$ 存在比表面积过小、表面活性位点较少、光生载流 子复合率较高、量子效率低以及带隙过小而无法充 分利用 $460 \mathrm{~nm}$ 以上的可见光等问题, 这在很大程度 上限制了 $\mathrm{g}-\mathrm{C}_{3} \mathrm{~N}_{4}$ 的实际应用效果。因此研究人员针 对这种情况提出了多种 $\mathrm{g}_{-} \mathrm{C}_{3} \mathrm{~N}_{4}$ 的改进方案:

(1)优化制备方法和前驱体: 在 $\mathrm{g}-\mathrm{C}_{3} \mathrm{~N}_{4}$ 的合成过 程中, 选用不同的前驱体和合成参数(如图 5(a)所示) 所获得的 $g-\mathrm{C}_{3} \mathrm{~N}_{4}$ 具有不同的比表面积和禁带宽度 ${ }^{[3]}$ 。

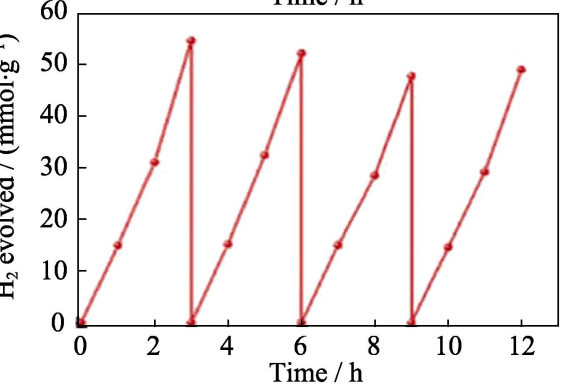

(b)

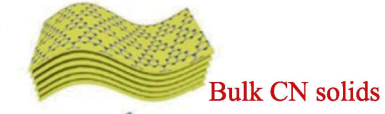

Top-down Lay-by-lay exfoliation

specific surface area nd different band gaps
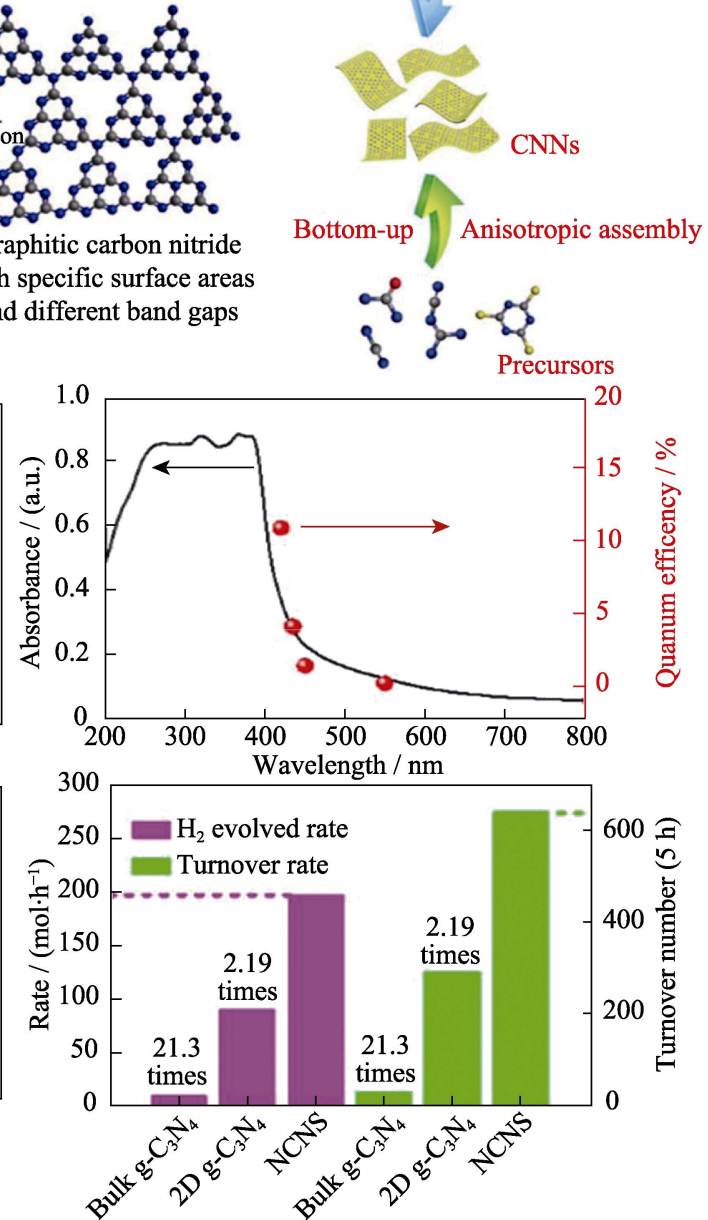

图 $5 \mathrm{~g}-\mathrm{C}_{3} \mathrm{~N}_{4}$ 的催化性能改性方法

Fig. 5 Catalytic performance modification methods of $\mathrm{g}-\mathrm{C}_{3} \mathrm{~N}_{4}$

(a) Different precursors and synthetic parameters affect the specific surface area and band gap of $\mathrm{g}_{-} \mathrm{C}_{3} \mathrm{~N}_{4}{ }^{[6]}$, (b) preparation of two-dimensional g- $_{3} \mathrm{~N}_{4}$ nanosheets by nanocrystallization ${ }^{[60]}$, and (c) effect of $\mathrm{N}$ doping on the photocatalytic hydrogen separation performance of $\mathrm{g}^{\mathrm{C}} \mathrm{C}_{3} \mathrm{~N}_{4}{ }^{[61]}$ 
这说明通过改进合成方法可以有效调控 $\mathrm{g}-\mathrm{C}_{3} \mathrm{~N}_{4}$ 能 带结构和表面性质, 从而改善其光催化性能。

(2)纳米化处理: 制备纳米尺寸的 $\mathrm{g}-\mathrm{C}_{3} \mathrm{~N}_{4}$, 如介 孔结构的 $\mathrm{g}-\mathrm{C}_{3} \mathrm{~N}_{4}$ 和低维结构的 ${ }^{\mathrm{g}}-\mathrm{C}_{3} \mathrm{~N}_{4}$ (如一维 $\mathrm{g}-\mathrm{C}_{3} \mathrm{~N}_{4}$ 纳米棒、二维 $\mathrm{g}-\mathrm{C}_{3} \mathrm{~N}_{4}$ 纳米片 $)^{[60,62]}$ 。如图 $5(\mathrm{~b})$ 所示, 二维 $\mathrm{g}-\mathrm{C}_{3} \mathrm{~N}_{4}$ 纳米片的合成制备主要有两种思 路：一种是“自上而下(Top-down)”的制备方法，指 的是采用化学氧化法、液相剥离法或者两者的结合 将 $\mathrm{g}-\mathrm{C}_{3} \mathrm{~N}_{4}$ 块材转变成层状 $\mathrm{g}-\mathrm{C}_{3} \mathrm{~N}_{4}$; 另一种则是“自 下而上(Bottom-up)” 的制备方法, 指的是使用模板 法等方法将有机分子组装成二维 $\mathrm{g}-\mathrm{C}_{3} \mathrm{~N}_{4}$ 纳米片。使 用高温热氧化或者超声处理的方法将块材 $\mathrm{g}-\mathrm{C}_{3} \mathrm{~N}_{4}$ 剥离成单层或者几层的二维 $\mathrm{g}-\mathrm{C}_{3} \mathrm{~N}_{4}$ 纳米片之后, 纳 米片结构与块材相比具有更大的比表面积和更多的 表面活性位点, 也可以相应地降低表面上光生空穴 和电子的复合率, 从而改善 $\mathrm{g}-\mathrm{C}_{3} \mathrm{~N}_{4}$ 光催化性能。

(3)掺杂: 按元素可以分为金属掺杂和非金属掺 杂。金属元素掺杂主要包括 $\mathrm{Fe} 、 \mathrm{Ni} 、 \mathrm{Cu}$ 等, 此类金 属元素掺杂到 $\mathrm{g}-\mathrm{C}_{3} \mathrm{~N}_{4}$ 结构单元中, 可以捕获光生载 流子, 延缓光生电子和空穴的复合, 从而提高其光 催化性能; 非金属掺杂主要包括 $\mathrm{O} 、 \mathrm{~N} 、 \mathrm{P} 、 \mathrm{~S}$ 等, 一 般认为庚嗪环中的 $\mathrm{C} 、 \mathrm{~N} 、 \mathrm{H}$ 元素被这些非金属元 素取代后形成晶格缺陷, 可实现光生载流子的高效 分离, 最终达到提高 $\mathrm{g}-\mathrm{C}_{3} \mathrm{~N}_{4}$ 光催化性能的目的(如 图 5 (c)所示) ${ }^{[61,63-64]}$ 。

(4)物理复合改性: 目前使用的最多、最为方便 的改进方法。一般使用 $\mathrm{g}-\mathrm{C}_{3} \mathrm{~N}_{4}$ 材料作为基底材料, 选择其他合适的半导体材料与其复合构建异质结结 构 $^{[65]}$ 。形成异质结结构之后, 复合体系中两种半导 体由于导带和价带之间的位置差异, $\mathrm{g}-\mathrm{C}_{3} \mathrm{~N}_{4}$ 中所产 生的光生电子和空穴将转移到半导体的导带和价带 中, 从而实现光激发电子和空穴在空间上的分离。电 子空穴对分离效率的提高, 可以大大降低电子和空 穴的复合率, 提高 $\mathrm{g}-\mathrm{C}_{3} \mathrm{~N}_{4}$ 的光催化效率。同时复合 之后体系的禁带宽度也将发生变化, 从而提高 $\mathrm{g}-\mathrm{C}_{3} \mathrm{~N}_{4}$ 对可见光的利用率。某些特殊半导体的掺杂 还能赋予 $\mathrm{g}-\mathrm{C}_{3} \mathrm{~N}_{4}$ 基异质结一些特殊的性质, 如磁性 和导电性等。

在过去几年内, 涌现出大量关于 $\mathrm{g}-\mathrm{C}_{3} \mathrm{~N}_{4}$ 基异质 结的研究和报道, 研究人员将铋氧卤化物 (如 $\mathrm{B}_{5} \mathrm{O}_{7} \mathrm{I} 、 \mathrm{BiOCl} 、 \mathrm{BiOBr}$ 等) ) $^{[66-68]}$ 、过渡金属硫化物(如

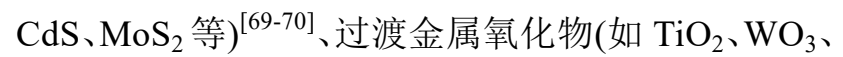

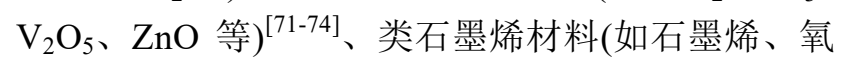
化石墨烯、碳纳米管等 $)^{[75-77]}$ 等与 $\mathrm{g}-\mathrm{C}_{3} \mathrm{~N}_{4}$ 复合构建 II 型异质结和 $\mathrm{Z}$ 型异质结, 用于催化 HER 反应、OER 反应、 $\mathrm{CO}_{2} \mathrm{RR}$ 反应以及降解有机染料等, 取得了很
大的进展。

\section{3 黑磷(BP)}

黑磷材料(BP) 是一种新兴的半导体材料, 二维 黑磷是磷单质的一种同素异形体。黑磷的研究可以 追溯到一个世纪以前, Bridgman 等在高温高压下成 功地将白磷和红磷转化成了黑磷晶体。作为单质磷 元素, 黑磷是常温常压最稳定的一种同素异形体。 黑磷与石墨类似, 都具有层状结构, 层与层之间也 是通过范德华力作用在一起的, 每一层上的磷原子 与邻近的三个磷原子通过 $\mathrm{sp}^{3}$ 杂化结合在一起, 构 成一个褶皱的蜂窝结构, 在这四个磷原子中, 其中 三个磷原子位于同一个面, 而第四个则位于平行的 面上。

2014 年, $\mathrm{Li}$ 等 ${ }^{[78]}$ 首次成功合成了二维黑磷结构, 引起了科学界的广泛关注。 $\mathrm{Li}$ 等 ${ }^{[79]}$ 首次提出黑磷可 做为光催化剂材料分解水制氢气, 并阐明了黑磷烯 电子结构与应变的关系; 通过量子分子动力学模拟 阐明了黑磷烯在水中的良好稳定性, 澄清了一直以 来黑磷烯在水中不稳定的误解。单层黑磷也称磷烯 或磷杂环戊烯, 可以通过机械剥离法从黑磷块材中剥 离, 如图 6 (a)所示。黑磷也是一种半导体材料, 具有极 高的空穴迁移率(约 $1000 \mathrm{~cm}^{2} \cdot \mathrm{V}^{-1} \cdot \mathrm{s}^{-1}$ ), 理论容量高达 $2596 \mathrm{mAh} \cdot \mathrm{g}^{-1}$, 在锂/钠电池的阳极材料中与单质 $\mathrm{Si}$ 具有可比性 ${ }^{[10]}$ 。黑磷各向异性的结构也赋予其各向 异性的光学性质和力学性质。更为重要的是, 黑磷 还具有可调节的带隙, 随着厚度的减小, 黑磷带隙 会相应增加, 块材黑磷的禁带宽度约为 $0.3 \mathrm{eV}$, 而 单层黑磷的禁带宽度约为 $2.0 \mathrm{eV}$, 表现出从可见光 到中红外区的宽泛光吸收窗口(如图 6 (b)所示 $)^{[80]}$ 。 这些特性赋予黑磷在光电、选择性传感器、催化和 电池等领域极大的应用前景 ${ }^{[81-82]}$ 。

作为一种二维半导体催化剂, 黑磷在催化 HER、OER 反应上均具有良好的表现。Wang 等 ${ }^{[83]}$ 第一次将黑磷应用于催化 OER 反应, 二维黑磷具有 极大的比表面积和丰富的活性位点, 同时某些本征 缺陷的存在, 也可以在一定程度上提高其催化效率。 此外, 黑磷还被用于催化光解水等其他反应。Majima 和其合作伙伴 ${ }^{[84]}$ 制备了 $\mathrm{BP} / \mathrm{Pt} / \mathrm{i}$ 还原氧化石墨烯三元 半导体用于光催化产氢, 黑磷充分吸收可见光和近 红外光, 产生光生电子, 电子通过 RGO 迁移, 而 $\mathrm{Pt}$ 纳米粒子则扮演助催化剂的作用, 结果显示 $\mathrm{BP} / \mathrm{Pt} / \mathrm{RGO}$ 体系的产氢速率远远高于 $\mathrm{Pt} / \mathrm{RGO}$ 复合 体系。DFT 理论计算的结果也表明, 黑磷可以作为 一种高效的光催化剂用于水分解 ${ }^{[85]}$ 。Yu 等 ${ }^{[86]}$ 曾构建 了黑磷/红磷异质结结构, 并在可见光下催化降解有 机污染物。 




图 6 黑磷块材到单层黑磷的(a)结构侧视图及其对应的(b)能带结构图 ${ }^{[80]}$

Fig. 6 Side view of (a) structure of black phosphorus block to monolayer black phosphorus and its corresponding (b) band structure diagram ${ }^{[80]}$

除了二维黑磷结构, 零维黑磷材料 (又称超小 黑磷纳米片) 的黑磷量子点 (BPQDs, Black phosphorus quantum dots), 由于量子限域效应和尺寸效 应表现出独特的光电性能, 也引起了学术界的重点 关注。Niu 等 ${ }^{[87]}$ DFT 研究表明, 单层 BPQDs 的带隙 与其尺寸之间存在明显的关联性, 随着 BPQDs 半 径的增大, 其禁带宽度降低并逐渐接近二维单层黑 磷的带隙。2015 年南洋理工大学张华老师团队 ${ }^{[88]}$ 第一次成功制备了 BPQDs，其尺寸约为 $(4.9 \pm 1.6) \mathrm{nm}$, 厚度约为 $(1.9 \pm 0.9) \mathrm{nm}$ 。同年, 深圳大学张晗教授课 题组 ${ }^{[89]}$ 也成功合成了超小 BPQDs, 其尺寸和厚度分 别达到(2.6 \pm 1.8$)$ 和(1.5 \pm 0.6$) \mathrm{nm}$ 。次年, 他们使用溶剂 热法又制备了尺寸约为 $(2.1 \pm 0.9) \mathrm{nm}$ 的 BPQDs ${ }^{[90]}$ 。

尽管黑磷和黑磷量子点表现出优异的光电特性 和良好的应用前景, 但是它们在自然环境中对空气 和水比较敏感, 极易被氧化分解, 从而严重影响其 实际应用。Gao 等 ${ }^{[91]}$ 研究表明, BPQDs 与某些基质 复合后, BPQDs 会变得更加稳定。因此在实际应用 中也可以考虑将 BP 和 BPQDs 与某些半导体如 $\mathrm{g}-\mathrm{C}_{3} \mathrm{~N}_{4}$ 复合, 在增强黑磷体系材料稳定性的同时, 改善其催化性能。

2017 年, $\mathrm{Zhu}$ 等 ${ }^{[92]}$ 将 $\mathrm{BP}$ 纳米片与 $\mathrm{g}-\mathrm{C}_{3} \mathrm{~N}_{4}$ 纳米片 复合构建二元纳米复合体系, 用于光催化产氢, 这 也是首次尝试将 $\mathrm{BP}$ 和 $\mathrm{g}-\mathrm{C}_{3} \mathrm{~N}_{4}$ 组合构建二维/二维复 合体系。由于该二元半导体光催化剂中只存在 P、C、 $\mathrm{N} 、 \mathrm{H}$ 等地球上储量丰富的非金属元素, 对于能源环 境的持续发展具有重大意义。然后, Qiu 等 ${ }^{[93]}$ 将 $\mathrm{BP}$
纳米片引入 $\mathrm{g}-\mathrm{C}_{3} \mathrm{~N}_{4}$ 中作为助催化剂, 可以吸收并利 用可见光以及近红外光波长范围的光, 实现高效稳 定的光催化固氮合成氨和重金属离子的还原。值得 注意的是, 通过与 $\mathrm{g}-\mathrm{C}_{3} \mathrm{~N}_{4}$ 复合, $\mathrm{BP}$ 纳米片的稳定性 也得到了强化。近年来, Ran 等 ${ }^{[94]}$ 也发现 $\mathrm{BP} / \mathrm{g}-\mathrm{C}_{3} \mathrm{~N}_{4}$ 复合体系的光催化产氢效率得到提高, 说明 BP 的 存在可以增强 $\mathrm{g}-\mathrm{C}_{3} \mathrm{~N}_{4}$ 的催化活性。2018 年, Kong 等 ${ }^{[95]}$ 将 BPQDs 与单层 $\mathrm{g}_{-} \mathrm{C}_{3} \mathrm{~N}_{4}$ 复合, 在可见光下完 成了高效催化析氢, 这也是 $\mathrm{BPQDs}$ 与 $\mathrm{g}_{-} \mathrm{C}_{3} \mathrm{~N}_{4}$ 复合 用于催化的第一次尝试。Liu 等 ${ }^{[96]}$ 也发现 BPQDs 的 存在利于 $\mathrm{g}-\mathrm{C}_{3} \mathrm{~N}_{4}$ 光催化析氢活性的提升。除了析氢 反应, $\mathrm{Han}$ 等 ${ }^{[97]}$ 也成功将 $\mathrm{BPQDs} / \mathrm{g}-\mathrm{C}_{3} \mathrm{~N}_{4}$ 复合体系用 于光还原 $\mathrm{CO}_{2} \rightarrow \mathrm{CO}$ 过程。

\section{2 二维材料催化性能的改性}

二维材料自诞生以来，便被广泛地应用于催化 领域。研究人员对各种二维功能材料催化剂提出了 多种改进方法, 对其催化性能进行调控, 例如边界 态调控(图 7 (a))、官能团调控(图 7 (b))、缺陷态调 控(图 7 (c))、单原子负载(图 7 (d))、二维材料限域 效应(图 7 (e)) 以及构建异质结(图 7 (f)) 等方法。

\section{1 边界态调控}

二维材料边缘上的原子所处的化学环境与基体 平面不同, 基体平面一般具有饱和配位, 而边缘具 有较大的非饱和配位倾向, 因此边缘位点对二维材 料的催化活性起着重要作用。二维过渡金属硫化物 
(a)

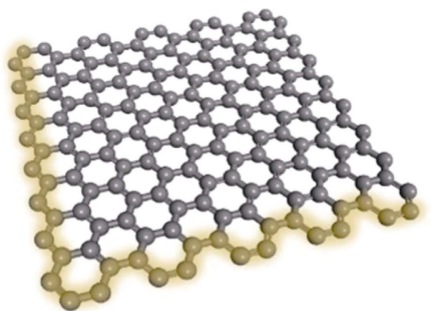

(d)

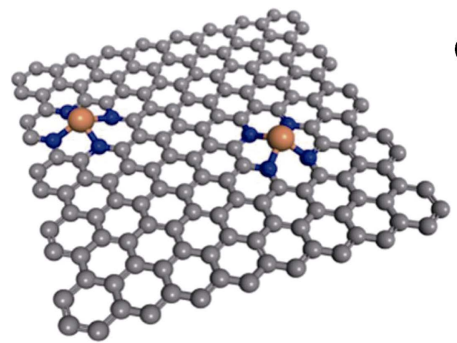

(b)

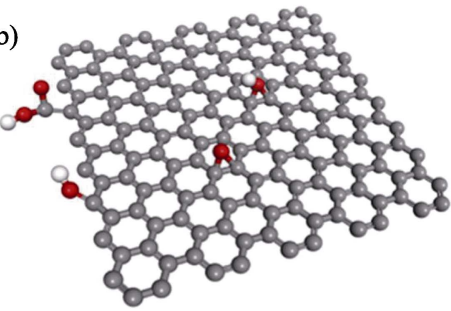

(e)

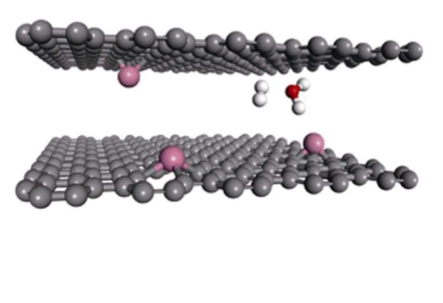

(c)

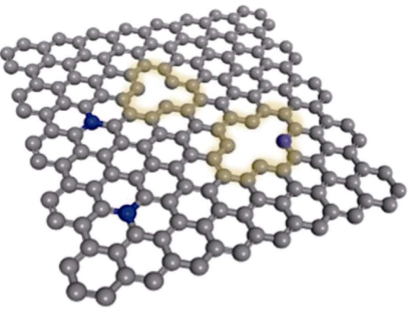

(f)

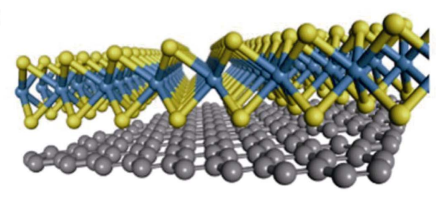

图 7 二维材料催化性能的改性

Fig. 7 Modification of catalytic properties of two-dimensional materials

(a) Boundary state regulation; (b) Functional group regulation; (c) Defect state regulation; (d) Single atomic immobilization; (e) Confinement effect; (f) Heterojunction

的催化活性位点基本都位于边界上，研究人员通过 增加外露边缘位置, 增强了 $\mathrm{MoS}_{2}$ 的 HER 活性 ${ }^{[98]}$ 。除 此之外, Deng 等 ${ }^{[99]}$ 研究表明, 在石墨烯材料中, 锯 齿边(Zigzag)对 ORR 反应具有催化活性, 而扶手椅 边(Armchair)的催化活性则较低, 通过球磨法将石 墨烯纳米片切碎, 提升锯齿边的密度, 可以有效提 升 ORR 催化活性。

\section{2 官能团调控}

官能团的存在对于二维材料的催化活性也有着 重要影响。在石墨烯表面引入含氧官能团, 构造氧 化石墨烯(GO)和还原氧化石墨烯(RGO)也可以提高 石墨烯的催化性能。Bielawski 等 ${ }^{[100]}$ 研究发现 GO 可以用于催化氧化各种有机化合物; Gao 等 ${ }^{[101]}$ 研究 也表明, RGO 可以有效催化硝基苯的氢化反应; $\mathrm{Du}$ 课题组 ${ }^{[102]}$ 的研究表明, 对于 MXene 材料而言, 表 面存在-O 官能团时, HER 催化活性优于表面无官能 团修饰的 MXene; Li 课题组 ${ }^{[41]}$ 研究发现通过调控 MXene 表面的官能团, 可以有效调控 $\mathrm{CO}_{2}$ 转化的稳 定性和选择性。

\section{3 缺陷态调控}

晶格缺陷，如空位、杂质原子等的存在可以对 二维功能材料的催化性能产生重要影响。Jiao 等 ${ }^{[103]}$ 通过改变温度获得了具有 $\mathrm{Zn}$ 原子空位的二维 $\mathrm{ZnIn}_{2} \mathrm{~S}_{4}$ 纳米片, 而 $\mathrm{Zn}$ 原子空位使得材料表现出极 高的电子-空穴分离效率, 光催化还原 $\mathrm{CO}_{2}$ 的活性 增加了 3.6 倍。在石墨烯中掺杂 $\mathrm{N} 、 \mathrm{~B} 、 \mathrm{P} 、 \mathrm{~S}$ 等杂质 原子也是石墨烯催化领域的重要研究方向 ${ }^{[104]}$ 。Sheng 等 ${ }^{[105]}$ 通过在石墨烯中掺杂 $\mathrm{B}$ 原子形成 $\mathrm{B}$ 掺杂石墨
烯, 杂质原子 $\mathrm{B}$ 成为催化的活性位点, 大大提高了 石墨烯材料的 OER 催化活性。

\section{4 单原子负载}

将催化剂以纳米颗粒的形式分散在二维材料表 面可以大大减少其消耗量, 如果催化剂可以 $100 \%$ 地 分散也能形成单原子催化。由于其良好的催化选择 性和可调节的电学性能, 单原子催化剂被广泛应用 于气体的催化转化反应。二维材料由于几何和电子 特性独特不仅可以直接作为催化剂, 而且是一类理 想的催化载体。最近, 为了解决单原子的团聚问题, 二维材料缺陷态被广泛应用于单原子催化剂或团簇 的固载, 例如 $\mathrm{N}$ 掺杂石墨烯可以通过独特的 TM-N-C 结构来针固金属单原子催化剂 ${ }^{[106]}$, 含有 $\mathrm{N}$ 缺陷的 h-BN 以及 $\mathrm{g}-\mathrm{C}_{3} \mathrm{~N}_{4}$ 等材料也是较好的单原子 负载材料 ${ }^{[107-108]}$ 。 $\mathrm{Li}$ 等 ${ }^{[108]}$ 利用缺陷辅助单原子负载 在 $\mathrm{g}-\mathrm{C}_{3} \mathrm{~N}_{4}$ 上, 在温和条件下将 $\mathrm{N}_{2}$ 活化为氨, 并提出 了单原子负载 $\mathrm{g}-\mathrm{C}_{3} \mathrm{~N}_{4}$ 人工合成氨的配位理论。

\section{5 二维材料限域效应}

利用二维材料的限域效应可固定单原子催化剂, 而限域的单原子也可以提升或者激活二维材料的本 征催化活性。限域是在二维材料层间的客体材料 HOMO 和 LUMO 能级处于二维材料的价带顶和导 带底, 从能级结构上分析, 层间客体材料的电子被 限域在层间, 形成一种能阱的结构, 从而使其稳定 地固定在二维材料中。同时处于限域空间中的单原 子催化剂, 可以通过 (1)扩大层间间距, 增大电化学 活性比表面积, 促进反应物和产物的扩散; (2)单原 子改变二维材料的表面陷阱态, 通过增强活性位点 
的固有催化活性来增加催化剂的活性位点 ${ }^{[109-110]}$ 。石 墨烯限域金属 $\mathrm{CoN}_{4}$ 中心在染料敏化太阳能电池的 对电极还原反应中, 可同时保证良好的催化活性和 稳定性 ${ }^{[111]}$ 。此外，二维材料与金属表面也能形成某 些限域空间，如 Zhang 等 ${ }^{[112]}$ 研究表明，在 h-BN二 维结构与 Pt(111)面间形成的限域空间内, 有效地促 进 $\mathrm{CO}$ 的氧化反应。限域空间的存在可以对分子的 活化产生重要影响, 最近有许多很好的工作支撑了 这一论断。如, Xie 等 ${ }^{[113]}$ 提出限制片层结构中巨大 的电子-空穴效应活化分子氧的机制; Bao 等 ${ }^{[114]}$ 利 用界面限域效应对催化体系结构和电子特性的影 响作用, 改善了在催化过程中传统非均相催化剂容 易出现的催化活性中心的失活以及催化功能失效 的问题。

\section{6 构建异质结}

将二维材料与其他材料复合构建异质结构也是 改善其催化活性的有效途径之一。目前学术界根据 异质结的电子结构(带隙大小、半导体的导带价带位 置)将异质结分为三类: I 型异质结、II 型异质结、III 型异质结 ${ }^{[115]}$ 。如图 8 所示, 对于 I 型异质结, 窄带 隙的半导体材料导带底和价带顶均位于宽禁带半导 体材料的禁带内, 在能量大于等于半导体禁带宽度
的光照下所产生的所有光生电子-空穴对, 将转移 并积聚在其中一个半导体上。因为光生载流子仍位 于同一个半导体上，I 型异质结的形成对电荷分离 并没有明显的增强，反而会降低光催化氧化还原反 应效率。对于 II 型异质结, 两个异质结的导带底和 价带顶交错排布，两个半导体的能带一般会形成向 上或向下的带边弯曲, 使得光生电子和空穴向不同 方向迁移，从而实现电子空穴对在异质结不同部位 的分离，减缓电子和空穴的复合，延长了自由电子 和空穴的存在时间，此时氧化还原反应在异质结的 不同半导体表面上进行 ${ }^{[116]}$ 。而对于III型异质结，两 种半导体的禁带完全错开，其中一种半导体的导带 底和价带顶都高于另一种半导体的导带底, 两种半 导体之间一般不会存在光生载流子的转移。除了上 述三种异质结之外, 还存在一种 $\mathrm{Z}$ 型异质结, 与 II 型异质结相同的是，两种半导体的导带价带边也呈 交错排布，不同的是，在 $\mathrm{Z}$ 型异质结中，电子由半 导体 2(导带底位置较低的半导体)的导带底向半导 体 1(导带底位置较高的半导体)的价带顶转移(图 8 (d)); 而在 II 型异质结中, 电子由半导体 1 的导带底 向半导体 2 的导带底转移, 空穴由半导体 2 的价带 顶向半导体 1 的价带顶转移。 $\mathrm{Z}$ 型异质结按照结构 (a)



Straddling (type-- $)$ (b)

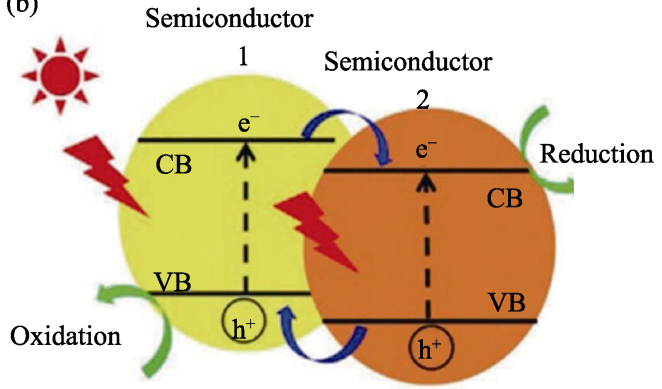

Staggered (type-II)



Broken gap (type- III)

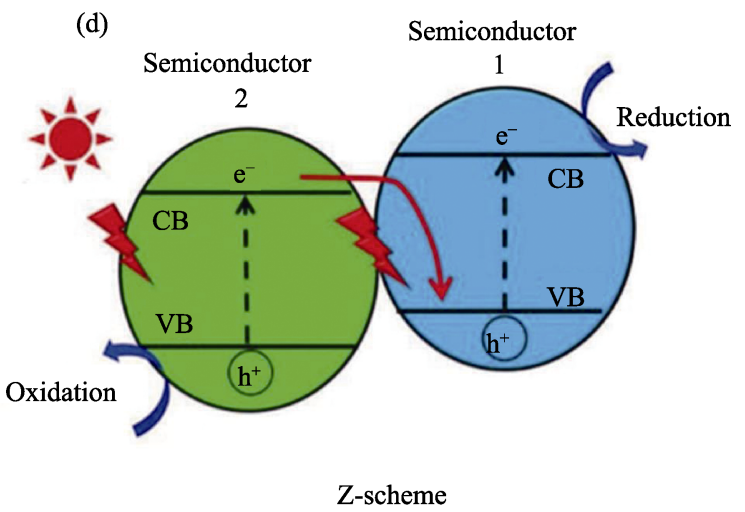

图 8 (a) I 型、 (b) II 型、(c)III型和(d)Z 型异质结光生电子传输示意图 ${ }^{[115]}$

Fig. 8 Schematic diagram of photogenerated electron transport of (a) type I, (b) type II, (c) type III and (d) Z type heterojunction ${ }^{[115]}$ 
可以分为半导体-半导体、半导体-供受体-半导体、 半导体-导体-半导体 $\mathrm{Z}$ 型异质结。构建 II 型异质结 和 $\mathrm{Z}$ 型异质结均能提高半导体的光吸收带宽, 并实 现光生载流子的空间分离, 提高材料的光催化效 率。此外, 应变工程可以将 I 型的异质结调控为 II 型异质结, 从而提高其光电转换效率 ${ }^{[117]}$ 。

前述重点论述了 $\mathrm{g}-\mathrm{C}_{3} \mathrm{~N}_{4}$ 基异质结在催化领域 的优秀表现。除此之外, Zhou 等 ${ }^{[118]}$ 曾对大量无机化 合物进行篮选, 设计出 36 种二维层状结构, 根据其 结构和能带的合理匹配, 设计了 44 种具有光解水催 化潜力的范德华异质结。这些通过数据库篮选和理 论预测所获得的异质结结构在实验制备上具有可行 性, 也为二维材料异质结的研究提供了研究方向。 $\mathrm{Li}$ 等 ${ }^{[119]}$ 利用第一性原理计算的方法, 构建一个接近 真实的黑磷量子点负载石墨相碳氮 $\left(\mathrm{BPQD} / \mathrm{g}-\mathrm{C}_{3} \mathrm{~N}_{4}\right)$ 异质结结构模型(如图 9 所示), 对其进行了结构优 化和性能研究, 计算了其形成能、电子结构、差分 电荷密度、局域电荷分布等重要性质, 探究了此复 合体系的异质结本质和增强光催化性能的机理。研 究表明, $\mathrm{BPQD} / \mathrm{g}-\mathrm{C}_{3} \mathrm{~N}_{4}$ 异质结结构为一个范德华异 质结, $\mathrm{BPQD}$ 与 $\mathrm{g}-\mathrm{C}_{3} \mathrm{~N}_{4}$ 纳米片之间通过范德华力结 合。两个半导体之间构成一个错列的能带结构, 形 成的 $0 \mathrm{D} / 2 \mathrm{D}$ 异质结属于 II 型异质结。在此纳米异质 结结构中, 光生电子由 BPQD 向 $\mathrm{g}-\mathrm{C}_{3} \mathrm{~N}_{4}$ 表面迁移, 而光生空穴迁移方向与其相反, 电子和空穴在分布 上的差异也使得氧化反应和还原反应在不同半导体 上进行。BPQD 和 $\mathrm{g}-\mathrm{C}_{3} \mathrm{~N}_{4}$ 形成异质结将大大改善其 光催化性能, 因为光生载流子在空间分布上的分离 可以降低电子-空穴对的复合率，从而促进光催化 氧化还原反应的发生。形成异质结之后, BPQD 的稳 定性得到进一步增强, $\mathrm{g}-\mathrm{C}_{3} \mathrm{~N}_{4}$ 纳米片的光催化活性 和光利用效率也得到有效提升。

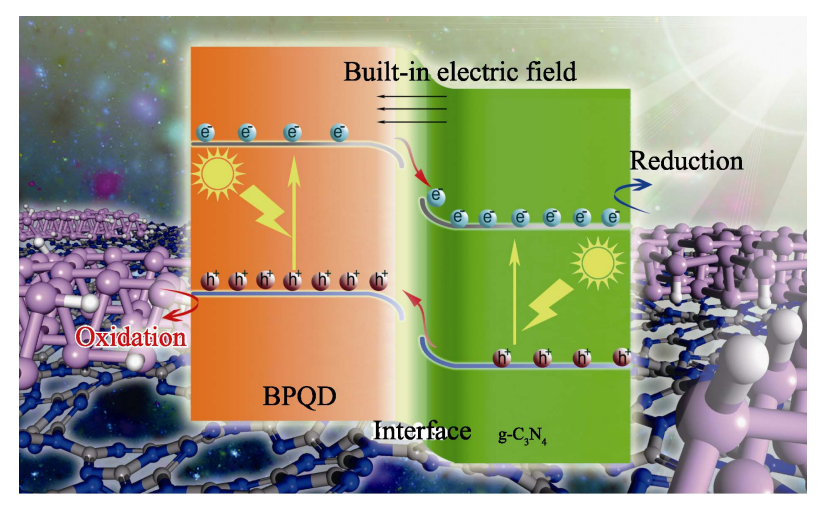

图 $9 \mathrm{BPQD} / \mathrm{GCN}$ 异质结的 II 型光催化反应机理示意图 ${ }^{[119]}$ Fig. 9 Type II photocatalytic reaction mechanism of BPQD/GCN heterojunction $^{[119]}$

\section{3 结束语}

随着社会的不断发展，能源与环境问题正深深 地困扰着人们，新材料和新能源的使用已被视为最 重要的解决方案之一。二维材料因其在光电催化领 域优异的性能, 受到许多研究人员的关注。虽然近年 对其催化性能的研究已取得了较大发展, 但还远远 未达到实用化的标准。

首先，就二维材料的合成来说，改善现有的合 成方法, 提出新的修饰理论, 发展多样高效的合成 技术是目前二维材料领域的一个重要研究方向。科 研工作者们还发展了一些特殊的合成方法, 定向吸 附合成法等。当然, 除了高效合成材料之外, 健全调 控策略的普适性准则, 完善二维结构的厚度、掺杂、 形变以及缺陷结构同电子结构之间的构效关系, 建 立宏观性质同微观结构间明确对应的理论模型, 实 现构建精准可控的修饰结构。其次，以二维材料的 种类来说, 目前大多数的二维材料可归属于石墨烯 类、氧基半导体、硫属半导体和碳氮化物等。相比 于传统的半导体光催化和电催化材料来说, 二维金 属性材料以极其优异的电学性能, 以及二维结构的 特点, 在催化、储能、复合材料中得到应用, 从而成 为二维结构材料家族重要的一员。最后, 如何在保 证材料稳定性的同时改善其催化性能依旧是当前二 维材料光催化或电催化领域的主要理论研究方向。 目前已提出了许多催化性能的改进方式, 主要为边 界态调控、官能团调控、缺陷态调控、单原子负载、 二维材料限域效应以及构建异质结等。这些改性手 段各有其适用范围与优势，应合理选择，搭配组合， 在不断试验中找到最佳方案。虽然还有非常多的工 作亟待解决，但这代表着二维材料光催化或电催化 这个新兴领域值得我们去探索。

\section{参考文献:}

[1] GEIM A K, NOVOSELOV K S. The rise of graphene. Nature Mater., 2007, 6: 183-191.

[2] 傅强, 包信和. 石墨烯的化学研究进展. 科学通报, 2009, 54(18): 2657-2666.

[3] ONG W J, TAN L L, NG Y H, et al. Graphitic carbon nitride $\left(\mathrm{g}-\mathrm{C}_{3} \mathrm{~N}_{4}\right)$-based photocatalysts for artificial photosynthesis and environmental remediation: are we a step closer to achieving sustainability? Chemical Reviews, 2016, 116 (12): 7159-7329.

[4] THOMAS A, FISCHER A, GOETTMANN F, et al. Graphitic carbon nitride materials: variation of structure and morphology and their use as metal-free catalysts. Journal of Materials Chemistry, 2008, 18(41): 4893.

[5] 张金水, 王博, 王心晨. 石墨相氮化碳的化学合成及应用. 物理 化学学报, 2013, 29(9): 1865-1876. 
[6] LUKATSKAYA M R, MASHTALIR O, REN C E, et al. Cation intercalation and high volumetric capacitance of two-dimensional titanium carbide. Science, 2013, 341(6153): 1502-1505.

[7] NAGUIB M, COME J, DYATKIN B, et al. MXene: a promising transition metal carbide anode for lithium-ion batteries. Electrochemistry Communications, 2012, 16(1): 61-64.

[8] PENG J, CHEN X, ONG W J, et al. Surface and heterointerface engineering of 2D MXenes and their nanocomposites: insights into electro- and photocatalysis. Chem., 2019, 5(1): 18-50.

[9] CHHOWALLA M, LIU Z, ZHANG H. Two-dimensional transition metal dichalcogenide (TMD) nanosheets. Chemical Society Reviews, 2015, 44(9): 2584-2586.

[10] CHHOWALLA M, SHIN H S, EDA G, et al. The chemistry of two-dimensional layered transition metal dichalcogenide nanosheets. Nature Chemistry, 2013, 5: 263.

[11] XU M, LIANG T, SHI M, et al. Graphene-like two-dimensional materials. Chemical Reviews, 2013, 113(5): 3766-3798.

[12] CHEN P, LI N, CHEN X, et al. The rising star of 2D black phosphorus beyond graphene: synthesis, properties and electronic applications. 2D Materials, 2017, 5(1): 014002.

[13] 袁振洲, 刘丹敏, 田楠, 等. 二维黑磷的结构、制备和性能. 化 学学报, 2016, 74(6): 488-497.

[14] LIN Y, WILLIAMS T V, CONNELL J W. Soluble, exfoliated hexagonal boron nitride nanosheets. The Journal of Physical Chemistry Letters, 2010, 1(1): 277-283.

[15] SONG L, CI L, LU H, et al. Large scale growth and characterization of atomic hexagonal boron nitride layers. Nano Letters, 2010, 10(8): 3209-3215.

[16] GONG M, LI Y, WANG H, et al. An advanced Ni-Fe layered double hydroxide electrocatalyst for water oxidation. Journal of the American Chemical Society, 2013, 135(23): 8452-8455.

[17] WANG Q, O'HARE D. Recent advances in the synthesis and application of layered double hydroxide (LDH) nanosheets. Chemical Reviews, 2012, 112(7): 4124-4155.

[18] OSADA M, SASAKI T. Exfoliated oxide nanosheets: new solution to nanoelectronics. Journal of Materials Chemistry, 2009, 19(17): 2503-2511.

[19] PENG Y, LI Y, BAN Y, et al. Metal-organic framework nanosheets as building blocks for molecular sieving membranes. Science, 2014, 346(6215): 1356

[20] RODENAS T, LUZ I, PRIETO G, et al. Metal-organic framework nanosheets in polymer composite materials for gas separation. $\mathrm{Na}$ ture Materials, 2014, 14: 48.

[21] PENG Y, HUANG Y, ZHU Y, et al. Ultrathin two-dimensional covalent organic framework nanosheets: preparation and application in highly sensitive and selective DNA detection. Journal of the American Chemical Society, 2017, 139(25): 8698-8704.

[22] KISSEL P, MURRAY D J, WULFTANGE W J, et al. A nanoporous two-dimensional polymer by single-crystal-to-single-crystal photopolymerization. Nature Chemistry, 2014, 6: 774.

[23] TAO L, CINQUANTA E, CHIAPPE D, et al. Silicene field-effect transistors operating at room temperature. Nature Nanotechnology, 2015, 10(3): 227-231.

[24] ZHANG S, YAN Z, LI Y, et al. Atomically thin arsenene and antimonene: semimetal-semiconductor and indirect-direct band-gap transitions. Angewandte Chemie International Edition, 2015, 54(10): 3112-3115.

[25] ZHANG T, DAR M I, LI G, et al. Bication lead iodide 2D perovskite component to stabilize inorganic $\alpha-\mathrm{CsPbI}_{3}$ perovskite phase for high-efficiency solar cells. Science Advances, 2017, 3(9): e1700841.

[26] TSAI H, NIE W, BLANCON J C, et al. High-efficiency two- dimensional Ruddlesden-Popper perovskite solar cells. Nature, 2016, 536(7616): 312-316.

[27] TAN C, CAO X, WU X J, et al. Recent advances in ultrathin twodimensional nanomaterials. Chem. Rev., 2017, 117(9): 6225-6331.

[28] ASHTON M, PAUL J, SINNOTT S B, et al. Topology-scaling identification of layered solids and stable exfoliated 2D materials. Physical Review Letters, 2017, 118(10): 106101.

[29] NAGUIB M, KURTOGLU M, PRESSER V, et al. Two-dimensional nanocrystals produced by exfoliation of $\mathrm{Ti}_{3} \mathrm{AlC}_{2}$. Advanced Materials, 2011, 23(37): 4248-4253.

[30] BARSOUM M W. The $\mathrm{M}_{N+1} \mathrm{AX}_{N}$ phases: a new class of solids: thermodynamically stable nanolaminates. Progress in Solid State Chemistry, 2000, 28(1): 201-281.

[31] HERN NDEZ S, MISKA P, GR N M, et al. Tailoring the surface density of silicon nanocrystals embedded in $\mathrm{SiO}_{x}$ single layers. Journal of Applied Physics, 2013, 114(23): 233101.

[32] SUN Z, LI S, AHUJA R, et al. Calculated elastic properties of $\mathrm{M}_{2} \mathrm{AlC}(\mathrm{M}=\mathrm{Ti}, \mathrm{V}, \mathrm{Cr}, \mathrm{Nb}$ and $\mathrm{Ta})$. Solid State Communications, 2004, 129(9): 589-592.

[33] GUO Z, ZHU L, ZHOU J, et al. Microscopic origin of MXenes derived from layered MAX phases. RSC Advances, 2015, 5(32): 25403-25408

[34] 李正阳，周爱国，王李波，等.二维晶体 MXene 的制备与性能 研究进展，硅酸盐通报, 2013,32(8): 1562-1566.

[35] NAGUIB M, MASHTALIR O, CARLE J, et al. Two-dimensional transition metal carbides. ACS Nano, 2012, 6(2): 1322-1331.

[36] MA T Y, CAO J L, JARONIEC M, et al. Interacting carbon nitride and titanium carbide nanosheets for high-performance oxygen evolution. Angewandte Chemie International Edition, 2016, 55(3): 1138-1142.

[37] ZHAO L, DONG B, LI S, et al. Interdiffusion reaction-assisted hybridization of two-dimensional metal-organic frameworks and $\mathrm{Ti}_{3} \mathrm{C}_{2} \mathrm{~T}_{x}$ nanosheets for electrocatalytic oxygen evolution. ACS Nano, 2017, 11(6): 5800-5807.

[38] YU M, ZHOU S, WANG Z, et al. Boosting electrocatalytic oxygen evolution by synergistically coupling layered double hydroxide with MXene. Nano Energy, 2018, 44: 181-190.

[39] ZHOU S, YANG X, PEI W, et al. Heterostructures of MXenes and $\mathrm{N}$-doped graphene as highly active bifunctional electrocatalysts. Nanoscale, 2018, 10(23): 10876-10883.

[40] ZHANG X, LEI J, WU D, et al. A Ti-anchored $\mathrm{Ti}_{2} \mathrm{CO}_{2}$ monolayer (MXene) as a single-atom catalyst for $\mathrm{CO}$ oxidation. Journal of Materials Chemistry A, 2016, 4(13): 4871-4876.

[41] LI N, CHEN X, ONG W J, et al. Understanding of electrochemical mechanisms for $\mathrm{CO}_{2}$ capture and conversion into hydrocarbon fuels in transition-metal carbides (MXenes). ACS Nano, 2017, 11(11): 10825-10833.

[42] AZOFRA L M, LI N, MACFARLANE D R, et al. Promising prospects for $2 \mathrm{D} d 2-\mathrm{d} 4 \mathrm{M}_{3} \mathrm{C}_{2}$ transition metal carbides (MXenes) in $\mathrm{N}_{2}$ capture and conversion into ammonia. Energy \& Environmental Science, 2016, 9(8): 2545-2549.

[43] ZHAO D, CHEN Z, YANG W, et al. MXene $\left(\mathrm{Ti}_{3} \mathrm{C}_{2}\right)$ vacancyconfined single-atom catalyst for efficient functionalization of $\mathrm{CO}_{2}$. Journal of the American Chemical Society, 2019, 141(9): 4086-4093.

[44] LING C, SHI L, OUYANG Y, et al. Searching for highly active catalysts for hydrogen evolution reaction based on O-terminated MXenes through a simple descriptor. Chemistry of Materials, 2016, 28(24): 9026-9032.

[45] GUO Z, ZHOU J, ZHU L, et al. MXene: a promising photocatalyst for water splitting. Journal of Materials Chemistry A, 2016, 4(29): 11446-11452. 
[46] LING C, SHI L, OUYANG Y, et al. Transition metal-promoted $\mathrm{V}_{2} \mathrm{CO}_{2}$ (MXenes): a new and highly active catalyst for hydrogen evolution reaction. Advanced Science, 2016, 3(11): 1600180.

[47] LI P, ZHU J, HANDOKO A D, et al. High-throughput theoretical optimization of the hydrogen evolution reaction on MXenes by transition metal modification. Journal of Materials Chemistry A, 2018, 6(10): 4271-4278.

[48] WANG H, PENG R, HOOD Z D, et al. Titania composites with 2D transition metal carbides as photocatalysts for hydrogen production under visible-light irradiation. ChemSusChem, 2016, 9(12): 1490-1497.

[49] RAN J, GAO G, LI F T, et al. $\mathrm{Ti}_{3} \mathrm{C}_{2}$ MXene co-catalyst on metal sulfide photo-absorbers for enhanced visible-light photocatalytic hydrogen production. Nature Communications, 2017, 8: 13907.

[50] SHAO M, SHAO Y, CHAI J, et al. Synergistic effect of 2D $\mathrm{Ti}_{2} \mathrm{C}$ and $\mathrm{g}_{-} \mathrm{C}_{3} \mathrm{~N}_{4}$ for efficient photocatalytic hydrogen production. Journal of Materials Chemistry A, 2017, 5(32): 16748-16756.

[51] SUN Y, JIN D, SUN Y, et al. g- $\mathrm{C}_{3} \mathrm{~N}_{4} / \mathrm{Ti}_{3} \mathrm{C}_{2} \mathrm{~T}_{x}$ (MXenes) composite with oxidized surface groups for efficient photocatalytic hydrogen evolution. Journal of Materials Chemistry A, 2018, 6(19): 9124-9131.

[52] PANDEY M, THYGESEN K S. Two-dimensional MXenes as catalysts for electrochemical hydrogen evolution: a computational screening study. The Journal of Physical Chemistry C, 2017, 121(25): 13593-13598.

[53] SEH Z W, FREDRICKSON K D, ANASORI B, et al. Two-dimensional Molybdenum Carbide (MXene) as an efficient electrocatalyst for hydrogen evolution. ACS Energy Letters, 2016, 1(3): 589-594.

[54] HUANG B, ZHOU N, CHEN X, et al. Insights into the electrocatalytic hydrogen evolution reaction mechanism on two-dimensional transition-metal carbonitrides (MXene). Chemistry, 2018, 24(69): 18479-18486.

[55] JIANG Y, SUN T, XIE X, et al. Oxygen-functionalized ultrathin $\mathrm{Ti}_{3} \mathrm{C}_{2} \mathrm{~T}_{x}$ MXene for enhanced electrocatalytic hydrogen evolution. ChemSusChem., 2019, 12(7): 1368-1373.

[56] TETER D M, HEMLEY R J. Low-compressibility carbon nitrides. Science, 1996, 271(5245): 53.

[57] KROKE E, SCHWARZ M, HORATH-BORDON E, et al. Tri-striazine derivatives. Part I. From trichloro-tri-s-triazine to graphitic $\mathrm{C}_{3} \mathrm{~N}_{4}$ structures. New Journal of Chemistry, 2002, 26(5): 508-512.

[58] WANG X, MAEDA K, THOMAS A, et al. A metal-free polymeric photocatalyst for hydrogen production from water under visible light. Nat. Mater, 2009, 8(1): 76-80.

[59] $\mathrm{CAO} \mathrm{S}, \mathrm{YU}$ J. g- $\mathrm{C}_{3} \mathrm{~N}_{4}$-based photocatalysts for hydrogen generation. The Journal of Physical Chemistry Letters, 2014, 5(12): 2101-2107.

[60] ZHANG J, CHEN Y, WANG X. Two-dimensional covalent carbon nitride nanosheets: synthesis, functionalization, and applications. Energy \& Environmental Science, 2015, 8(11): 3092-3108.

[61] HAO Q, SONG Y, JI H, et al. Surface N modified 2D g- $\mathrm{C}_{3} \mathrm{~N}_{4}$ nanosheets derived from DMF for photocatalytic $\mathrm{H}_{2}$ evolution. Applied Surface Science, 2018, 459: 845-852.

[62] CUI Y, ZHANG J, ZHANG G, et al. Synthesis of bulk and nanoporous carbon nitride polymers from ammonium thiocyanate for photocatalytic hydrogen evolution. Journal of Materials Chemistry, 2011, 21(34): 13032-13039.

[63] Bellardita M, GARC A L, PEZ E I, et al. Selective photocatalytic oxidation of aromatic alcohols in water by using P-doped $\mathrm{g}_{-} \mathrm{C}_{3} \mathrm{~N}_{4}$. Applied Catalysis B: Environmental, 2018, 220: 222-233.

[64] JOURSHABANI M, SHARIATINIA Z, BADIEI A. Synthesis and characterization of novel $\mathrm{Sm}_{2} \mathrm{O}_{3} / \mathrm{S}$-doped $\mathrm{g}^{-} \mathrm{C}_{3} \mathrm{~N}_{4}$ nanocomposites with enhanced photocatalytic activities under visible light irradiation. Applied Surface Science, 2018, 427: 375-387.

[65] FU J, YU J, JIANG C, et al. g- $\mathrm{C}_{3} \mathrm{~N}_{4}$-based heterostructured photocatalysts. Advanced Energy Materials, 2018, 8: 1701503.
[66] BAI Y, WANG P Q, LIU J Y, et al. Enhanced photocatalytic performance of direct Z-scheme BiOCl-g- $\mathrm{C}_{3} \mathrm{~N}_{4}$ photocatalysts. RSC Advances, 2014, 4(37): 19456-19461.

[67] DI J, XIA J, YIN S, et al. Preparation of sphere-like g- $\mathrm{C}_{3} \mathrm{~N}_{4} / \mathrm{BiOI}$ photocatalysts via a reactable ionic liquid for visible-light-driven photocatalytic degradation of pollutants. Journal of Materials Chemistry A, 2014, 2(15): 5340-5351.

[68] LIU C, HUANG H, DU X, et al. In situ co-crystallization for fabrication of $\mathrm{g}-\mathrm{C}_{3} \mathrm{~N}_{4} / \mathrm{Bi}_{5} \mathrm{O}_{7} \mathrm{I}$ heterojunction for enhanced visible-light photocatalysis. The Journal of Physical Chemistry C, 2015, 119(30): 17156-17165.

[69] LI G, WANG B, ZHANG J, et al. Rational construction of a direct $\mathrm{Z}$-scheme $\mathrm{g}-\mathrm{C}_{3} \mathrm{~N}_{4} / \mathrm{CdS}$ photocatalyst with enhanced visible light photocatalytic activity and degradation of erythromycin and tetracycline. Applied Surface Science, 2019, 478: 1056-1064.

[70] LIU Y, ZHANG H, KE J, et al. OD $\left(\mathrm{MoS}_{2}\right) / 2 \mathrm{D}\left(\mathrm{g}-\mathrm{C}_{3} \mathrm{~N}_{4}\right)$ heterojunctions in Z-scheme for enhanced photocatalytic and electrochemical hydrogen evolution. Applied Catalysis B: Environmental, 2018, 228: 64-74.

[71] HONG Y, JIANG Y, LI C, et al. In-situ synthesis of direct solidstate $\mathrm{Z}$-scheme $\mathrm{V}_{2} \mathrm{O}_{5} / \mathrm{g}-\mathrm{C}_{3} \mathrm{~N}_{4}$ heterojunctions with enhanced visible light efficiency in photocatalytic degradation of pollutants. Applied Catalysis B: Environmental, 2016, 180: 663-673.

[72] HUANG Z A, SUN Q, LYU K, et al. Effect of contact interface between $\mathrm{TiO}_{2}$ and $\mathrm{g}-\mathrm{C}_{3} \mathrm{~N}_{4}$ on the photoreactivity of $\mathrm{g}-\mathrm{C}_{3} \mathrm{~N}_{4} / \mathrm{TiO}_{2}$ photocatalyst: (001) vs (101) facets of $\mathrm{TiO}_{2}$. Applied Catalysis B: Environmental, 2015, 164: 420-427.

[73] WANG J, XIA Y, ZHAO H, et al. Oxygen defects-mediated $\mathrm{Z}$-scheme charge separation in $\mathrm{g}-\mathrm{C}_{3} \mathrm{~N}_{4} / \mathrm{ZnO}$ photocatalysts for enhanced visible-light degradation of 4-chlorophenol and hydrogen evolution. Applied Catalysis B: Environmental, 2017, 206: 406-416.

[74] YU W, CHEN J, SHANG T, et al. Direct Z-scheme g- $\mathrm{C}_{3} \mathrm{~N}_{4} / \mathrm{WO}_{3}$ photocatalyst with atomically defined junction for $\mathrm{H}_{2}$ production. Applied Catalysis B: Environmental, 2017, 219: 693-704.

[75] TIAN J, NING R, LIU Q, et al. Three-dimensional porous supramolecular architecture from ultrathin $\mathrm{g}_{-} \mathrm{C}_{3} \mathrm{~N}_{4}$ nanosheets and reduced graphene oxide: solution self-assembly construction and application as a highly efficient metal-free electrocatalyst for oxygen reduction reaction. ACS Applied Materials \& Interfaces, 2014, 6(2): 1011-1017.

[76] WANG C, ZHAO H, WANG J, et al. Atomic Fe hetero-layered coordination between $\mathrm{g}_{-} \mathrm{C}_{3} \mathrm{~N}_{4}$ and graphene nanomeshes enhances the ORR electrocatalytic performance of zinc-air batteries. Journal of Materials Chemistry A, 2019, 7(4): 1451-1458.

[77] XU L, HUANG W Q, WANG L L, et al. Insights into enhanced visible-light photocatalytic hydrogen evolution of $\mathrm{g}_{-} \mathrm{C}_{3} \mathrm{~N}_{4}$ and highly reduced graphene oxide composite: the role of oxygen. Chemistry of Materials, 2015, 27(5): 1612-1621.

[78] LI L, YU Y. Black phosphorus field-effect transistors. 2014, 9(5): 372-377.

[79] SA B, LI Y L, QI J, et al. Strain engineering for phosphorene: the potential application as a photocatalyst. The Journal of Physical Chemistry C, 2014, 118(46): 26560-26568.

[80] RAN J, ZHU B, QIAO S Z. Phosphorene co-catalyst advancing highly efficient visible-light photocatalytic hydrogen production. Angewandte Chemie International Edition, 2017, 56(35): 10373-10377.

[81] LIU H, DU Y, DENG Y, et al. Semiconducting black phosphorus: synthesis, transport properties and electronic applications. Chemical Society Reviews, 2015, 44(9): 2732-2743.

[82] LIU H, HU K, YAN D, et al. Recent advances on black phosphorus for energy storage, catalysis, and sensor applications. Advanced Materials, 2018, 30(32): e1800295. 
[83] JIANG Q, XU L, CHEN N, et al. Facile synthesis of black phosphorus: an efficient electrocatalyst for the oxygen evolving reaction. Angewandte Chemie International Edition, 2016, 55(44): 13849-13853.

[84] ZHU M, OSAKADA Y, KIM S, et al. Black phosphorus: a promising two dimensional visible and near-infrared-activated photocatalyst for hydrogen evolution. Applied Catalysis B: Environmental, 2017, 217: 285-292.

[85] DING K, WEN L, HUANG S, et al. Electronic properties of red and black phosphorous and their potential application as photocatalysts. RSC Advances, 2016, 6(84): 80872-80884.

[86] SHEN Z, SUN S, WANG W, et al. A black-red phosphorus heterostructure for efficient visible-light-driven photocatalysis. Journal of Materials Chemistry A, 2015, 3(7): 3285-3288.

[87] NIU X, LI Y, SHU H, et al. Anomalous size dependence of optical properties in black phosphorus quantum dots. The Journal of Physical Chemistry Letters, 2016, 7(3): 370-375.

[88] ZHANG X, XIE H, LIU Z, et al. Black phosphorus quantum dots. Angewandte Chemie International Edition, 2015, 54(12): 3653- 3657.

[89] SUN Z, XIE H, TANG S, et al. Ultrasmall black phosphorus quantum dots: synthesis and use as photothermal agents. Angewandte Chemie International Edition, 2015, 54(39): 11526-11530.

[90] XU Y, WANG Z, GUO Z, et al. Solvothermal synthesis and ultrafast photonics of black phosphorus quantum dots. Advanced $O p$ tical Materials, 2016, 4(8): 1223-1229.

[91] GAO J, ZHANG G, ZHANG Y W. The critical role of substrate in stabilizing phosphorene nanoflake: a theoretical exploration. $\mathrm{J}$. Am. Chem. Soc., 2016, 138(14): 4763-4771.

[92] ZHU M, KIM S, MAO L, et al. Metal-free photocatalyst for $\mathrm{H}_{2}$ evolution in visible to near-infrared region: black phosphorus/graphitic carbon nitride. J. Am. Chem. Soc. 2017, 139(37): 13234-13242.

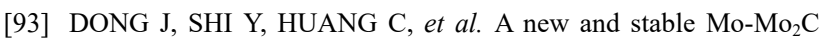
modified $\mathrm{g}-\mathrm{C}_{3} \mathrm{~N}_{4}$ photocatalyst for efficient visible light photocatalytic $\mathrm{H}_{2}$ production. Applied Catalysis B: Environmental, 2019, 243: $27-35$.

[94] RAN J, GUO W, WANG H, et al. Metal-free 2D/2D phosphorene/ g- $\mathrm{C}_{3} \mathrm{~N}_{4}$ van der waals heterojunction for highly enhanced visiblelight photocatalytic $\mathrm{H}_{2}$ production. Advanced Materials, 2018, 30(25): e1800128.

[95] KONG L, JI Y, DANG Z, et al. g- $\mathrm{C}_{3} \mathrm{~N}_{4}$ loading black phosphorus quantum dot for efficient and stable photocatalytic $\mathrm{H}_{2}$ generation under visible light. Advanced Functional Materials, 2018, 28(22): 1800668.

[96] LEI W, MI Y, FENG R, et al. Hybrid 0D-2D black phosphorus quantum dots-graphitic carbon nitride nanosheets for efficient hydrogen evolution. Nano Energy, 2018, 50: 552-561.

[97] HAN C, LI J, MA Z, et al. Black phosphorus quantum dot $/ \mathrm{g}-\mathrm{C}_{3} \mathrm{~N}_{4}$ composites for enhanced $\mathrm{CO}_{2}$ photoreduction to $\mathrm{CO}$. Science China Materials, 2018, 61(9): 1159-1166.

[98] TSAI C, ABILD-PEDERSEN F, N RSKOV J K. Tuning the $\mathrm{MoS}_{2}$ edge-site activity for hydrogen evolution via support interactions. Nano Letters, 2014, 14(3): 1381-1387.

[99] DENG D, YU L, PAN X, et al. Size effect of graphene on electrocatalytic activation of oxygen. Chemical Communications, 2011, 47(36): 10016-10018.

[100] DREYER D R, JIA H P, BIELAWSKI C W. Graphene oxide: a convenient carbocatalyst for facilitating oxidation and hydration reactions. Angewandte Chemie, 2010, 122(38): 6965-6968.

[101] GAO Y, MA D, WANG C, et al. Reduced graphene oxide as a catalyst for hydrogenation of nitrobenzene at room temperature. Chemical Communications, 2011, 47(8): 2432-2434.
[102] GAO G, O'MULLANE A P, DU A. 2D MXenes: a new family of promising catalysts for the hydrogen evolution reaction. $\mathrm{ACS} \mathrm{Ca}$ talysis, 2017, 7(1): 494-500.

[103] JIAO X, CHEN Z, LI X, et al. Defect-mediated electron-hole separation in one-unit-cell $\mathrm{ZnIn}_{2} \mathrm{~S}_{4}$ layers for boosted solar-driven $\mathrm{CO}_{2}$ reduction. Journal of the American Chemical Society, 2017, 139(22): 7586-7594.

[104] DENG D, NOvOSELOV K S, FU Q, et al. Catalysis with twodimensional materials and their heterostructures. Nature Nanotechnology, 2016, 11: 218.

[105] SHENG Z H, GAO H L, BAO W J, et al. Synthesis of boron doped graphene for oxygen reduction reaction in fuel cells. Journal of Materials Chemistry, 2012, 22(2): 390-395.

[106] XU H, CHENG D, CAO D, et al. A universal principle for a rational design of single-atom electrocatalysts. Nature Catalysis, 2018, 1(5): 339-348.

[107] ZHAO J, CHEN Z. Single Mo atom supported on defective boron nitride monolayer as an efficient electrocatalyst for nitrogen fixation: a computational study. Journal of the American Chemical Society, 2017, 139(36): 12480-12487.

[108] CHEN X, ZHAO X, KONG Z, et al. Unravelling the electrochemical mechanisms for nitrogen fixation on single transition metal atoms embedded in defective graphitic carbon nitride. Journal of Materials Chemistry A, 2018, 6(44): 21941-21948.

[109] WANG Y, ZHANG W, DENG D, et al. Two-dimensional materials confining single atoms for catalysis. Chinese Journal of Catalysis, 2017, 38: 1443-1453.

[110] HUANG L L, ZOU Y Q, CHEN D W, et al. Electronic structure regulation on layered double hydroxides for oxygen evolution reaction. Chinese Journal of Catalysis, 2019, 40(12): 1822-1840.

[111] CUI X, XIAO J, WU Y, et al. A graphene composite material with single cobalt active sites: a highly efficient counter electrode for dyesensitized solar cells. Angewandte Chemie International Edition, 2016, 128(23): 6820-6824.

[112] ZHANG Y, WENG X, LI H, et al. Hexagonal boron nitride cover on $\operatorname{Pt}(111)$ : a new route to tune molecule-metal interaction and metal-catalyzed reactions. Nano Letters, 2015, 15(5): 3616-3623.

[113] WANG H, CHEN S, YONG X, et al. Giant electron-hole interactions in confined layered structures for molecular oxygen activation. J. Am. Chem. Soc., 2017, 139(13): 4737-4742.

[114] FU Q, YANG F, BAO X. Interface-confined oxide nanostructures for catalytic oxidation reactions. Accounts of Chemical Research, 2013, 46(8): 1692-1701.

[115] LOW J, YU J, JARONIEC M, et al. Heterojunction photocatalysts. Advanced Materials, 2017, 29(20):1601694.

[116] LIAO J, SA B, ZHOU J, et al. Design of high-efficiency visiblelight photocatalysts for water splitting: $\mathrm{MoS}_{2} / \mathrm{AlN}(\mathrm{GaN})$ heterostructures. The Journal of Physical Chemistry C, 2014, 118(31): 17594-17599.

[117] GUO Z, MIAO N, ZHOU J, et al. Strain-mediated type-I/type-II transition in MXene/blue phosphorene van der Waals heterostructures for flexible optical/electronic devices. Journal of Materials Chemistry C, 2017, 5(4): 978-984.

[118] ZHANG X, ZHANG Z, WU D, et al. Computational screening of 2D materials and rational design of heterojunctions for water splitting photocatalysts. Small Methods, 2018, 2(5): 1700359.

[119] KONG Z, CHEN X, ONG W J, et al. Atomic-level insight into the mechanism of $0 \mathrm{D} / 2 \mathrm{D}$ black phosphorus quantum dot/graphitic carbon nitride $(\mathrm{BPQD} / \mathrm{GCN})$ metal-free heterojunction for photocatalysis. Applied Surface Science, 2019, 463: 1148-1153. 